\title{
Review
}

\section{Strain Engineering: A Pathway for Tunable Functionalities of Perovskite Metal Oxide Films}

\author{
Samyak Dhole ${ }^{1}$, Aiping Chen ${ }^{2}$, Wanyi Nie ${ }^{2}$, Baeho Park ${ }^{3}$ and Quanxi Jia ${ }^{1,3, *(\mathbb{D})}$ \\ 1 Department of Materials Design and Innovation, University at Buffalo-The State University of New York, \\ Buffalo, NY 14260, USA; sdhole@buffalo.edu \\ 2 Center for Integrated Nanotechnologies, Los Alamos National Laboratory, Los Alamos, NM 87545, USA; \\ apchen@lanl.gov (A.C.); wanyi@lanl.gov (W.N.) \\ 3 Division of Quantum Phases \& Devices, Department of Physics, Konkuk University, Seoul 05029, Korea; \\ baehpark@konkuk.ac.kr \\ * Correspondence: qxjia@buffalo.edu
}

check for updates

Citation: Dhole, S.; Chen, A.; Nie, W.; Park, B.; Jia, Q. Strain Engineering: A Pathway for Tunable Functionalities of Perovskite Metal Oxide Films. Nanomaterials 2022, 12, 835. https:// doi.org/10.3390/nano12050835

Academic Editors: Alexander Tselev and Edson Roberto Leite

Received: 19 January 2022 Accepted: 24 February 2022 Published: 1 March 2022

Publisher's Note: MDPI stays neutral with regard to jurisdictional claims in published maps and institutional affiliations.

Copyright: (C) 2022 by the authors. Licensee MDPI, Basel, Switzerland. This article is an open access article distributed under the terms and conditions of the Creative Commons Attribution (CC BY) license (https:// creativecommons.org/licenses/by/ $4.0 /)$.

\begin{abstract}
Perovskite offers a framework that boasts various functionalities and physical properties of interest such as ferroelectricity, magnetic orderings, multiferroicity, superconductivity, semiconductor, and optoelectronic properties owing to their rich compositional diversity. These properties are also uniquely tied to their crystal distortion which is directly affected by lattice strain. Therefore, many important properties of perovskite can be further tuned through strain engineering which can be accomplished by chemical doping or simply element substitution, interface engineering in epitaxial thin films, and special architectures such as nanocomposites. In this review, we focus on and highlight the structure-property relationships of perovskite metal oxide films and elucidate the principles to manipulate the functionalities through different modalities of strain engineering approaches.
\end{abstract}

Keywords: perovskite; metal oxides; lattice strain

\section{Introduction}

Perovskite has emerged as an important class of material in technologically important sectors. The research interests and application development of such materials have grown exponentially. Since many elements from the periodic table can be fitted into such a unique crystal structure [1], it is not an overstatement for us to envision that perovskite can be used as a framework to study a wide range of properties and functionalities including ferroic orderings, superconductivity, colossal magnetoresistance, optoelectronics, etc. [2]. Oxide perovskite thin films have been of particular interest in terms of both fundamental research and technological applications for oxide electronics [3]. Since the physical properties of such materials can be further affected by the chemical doping [4-7] and epitaxial strain [8-13], one can strain the materials to tune the properties of the materials towards specific applications. Recently, more approaches for strain engineering have come to the fore. Examples include mechanically straining free-standing single-crystalline membranes $[8,14]$ grown on the buffered substrate where the buffer layer can be etched off thereafter, and the ion implantation of species such as helium [15] and nitrogen [16] to strain the lattice. Perovskite materials have also garnered interest in a wide range of applications such as solar cells, photo/electrocatalysis, photopolymerization, thermoelectrics, resistive switching devices, etc. [17-25]. In this review, we will focus on the role of chemical pressure and epitaxial strain in perovskite metal oxide films, superlattices, and vertically aligned nanocomposites.

The ideal structure of perovskite with a chemical formula $\mathrm{ABO}_{3}$ is cubic, as shown in Figure $1 \mathrm{a}$, and composed of a three-dimensional network of corner-sharing $\left[\mathrm{BO}_{6}\right]$ octahedra, where the A cation sits in the cubo-octahedral site between adjacent octahedra. However, the structures of most perovskite materials exhibit a lower symmetry, such as rhombohedral, orthorhombic, or tetragonal [2]. The geometry and symmetry of the crystal structure are 
directly affected by the relative size of the comprising ions and often viewed through the proxy of Goldschmidt tolerance factor, $t$ :

$$
t=\frac{\mathrm{R}_{\mathrm{A}}+\mathrm{R}_{\mathrm{X}}}{\sqrt{2\left(\mathrm{R}_{\mathrm{B}}+\mathrm{R}_{\mathrm{X}}\right)}}
$$

(a)

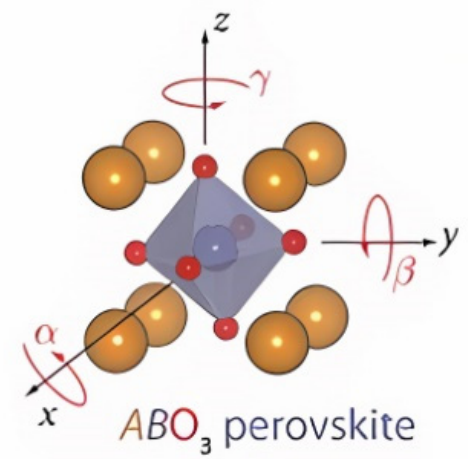

(b)

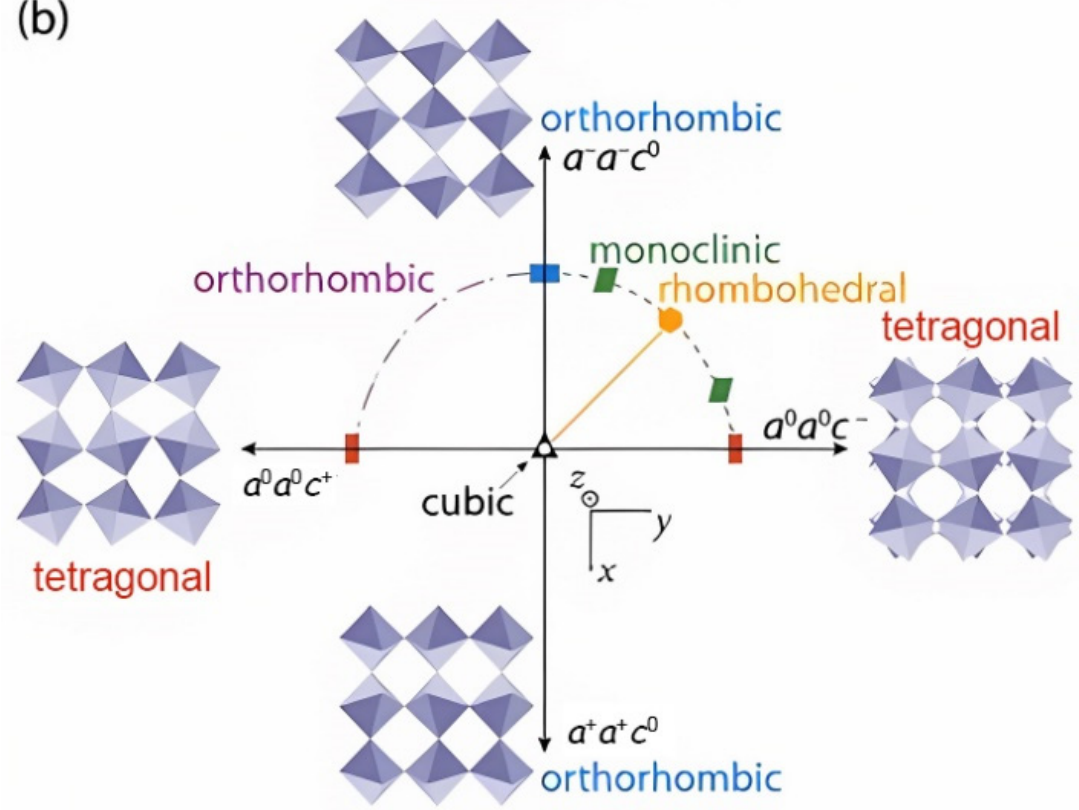

Figure 1. (a) The ideal $\mathrm{ABO}_{3}$ perovskite crystal structure showing tilt in all three directions. (b) Distortion of $\left[\mathrm{BO}_{6}\right]$ octahedra along various directions, lowering the symmetry of the cubic structure and forming other crystal structures. The positive sign indicates in-phase rotation $\left(\mathrm{c}^{+}\right)$and the negative sign shows out-of-phase rotation $\left(\mathrm{c}^{-}\right)$, both about $\mathrm{z}$-axis. Reprinted with permission from ref. [26]. Copyright 2011, Wiley.

For the ideal cubic aristotype, $t=1$. As $t$ lowers further, the structures distort via octahedral tilts and rotations, as shown in Figure $1 \mathrm{~b}$, to lower the symmetry until the perovskite phase stops being stable $[2,26]$. From the viewpoint of chemical compositions, the structure can therefore be distorted by doping isovalent elements of different sizes to exert a chemical pressure on the lattice.

Another way to affect the crystal structure is through epitaxial strain. While bulk crystals are brittle and fragile to mechanical strain, epitaxial thin films can tolerate strains of the order of several percent $[27,28]$. Such epitaxial thin films have a rich history in perovskite metal oxides facilitated by the advances in thin-film growth techniques such as molecular beam epitaxy, pulse laser deposition, sputtering, metal-organic chemical vapor deposition, and chemical solution deposition. Biaxial strains in perovskite metal oxide films can be used as a lever to tune physical properties such as electric polarization, magnetoresistance and 
magnetic anisotropy, and stabilize metastable phases [9]. Strain can distort the perovskite structure by tilting, rotating, and elongating the oxygen octahedra, and therefore significantly affect the properties of given materials such as Curie temperature $\left(T_{C}\right)[10,29-31]$, magnetic anisotropy [32-37], and magnetotransport properties of ferromagnetic materials [38-41]. In ferroelectric perovskite oxides, for example, the epitaxial strain can enhance the $\mathrm{T}_{\mathrm{C}}$ for several hundreds of degrees $[11,42-45]$. One of the best illustrations is probably $\mathrm{SrTiO}_{3}$, where the lattice strain can make $\mathrm{SrTiO}_{3}$ ferroelectric at room temperature, despite the unstrained $\mathrm{SrTiO}_{3}$ being paraelectric throughout all temperatures [13]. Similarly, epitaxial strain-engineering can also be leveraged in multilayer epitaxial heterostructures, i.e., epitaxial layered structures, superlattices, and vertically aligned nanocomposites (VANs). For example, ferroelectric $\mathrm{SrTiO}_{3}$ has been experimentally demonstrated in fully strained $\mathrm{SrTiO}_{3}$ films [13], superlattices $\mathrm{SrTiO}_{3} / \mathrm{BaZrO}_{3}$ [45] and $\mathrm{SrTiO}_{3} / \mathrm{BaTiO}_{3}$ [11], and vertically aligned epitaxial $\mathrm{SrTiO}_{3}: \mathrm{MgO}$ and $\mathrm{SrTiO}_{3}: \mathrm{Sm}_{2} \mathrm{O}_{3}$ nanocomposite films $[46,47]$.

\section{Strain Engineering through Chemical Substitution or Chemical Pressure}

The substitution of ions via chemical pressure is one of the common approaches to strain the crystal structure. As the A-site cations prefer to form close-shelled electronic configurations with fixed valency, they largely play a structural role. The cation size influences lattice constants, bond lengths and angles, and octahedral rotations and tilts. In other words, a distortion of the central $\left[\mathrm{BO}_{6}\right]$ octahedra can directly affect the material properties. Both the mean size and the size mismatch of the cations on the A-site affect the electronic and structural phase transitions [48-50].

To illustrate strain engineering to tune the functionalities of perovskites through chemical substitution or chemical pressure, we use $\mathrm{AMnO}_{3}$ manganates as the model system. Mixed-valent perovskite manganates, $\mathrm{AMnO}_{3}$, are one of the most widely studied systems for their colossal magnetoresistance (CMR) property. The Curie temperature of these materials, $T_{C}$, is very sensitive to the change in chemical pressure which can be introduced via the substitution of trivalent rare earth metals of different sizes. For example, as the atomic radius of the A cation changes from a relatively larger to a smaller size in the case of $\mathrm{La}, \mathrm{Pr}, \mathrm{Nd}$ and $\mathrm{Eu}$, and the Neel temperature, $\mathrm{T}_{\mathrm{N}}$, for the antiferromagnetic insulator phase is lowered with the change in the B-O-B angle away from $180^{\circ}$, as shown in Figure 2a [51]. In $\mathrm{Ln}_{1-x} \mathrm{M}_{\mathrm{x}} \mathrm{MnO}_{3}$ systems, where $\mathrm{Ln}=$ trivalent lanthanide $(\mathrm{La}, \mathrm{Pr}, \mathrm{Nd}, \ldots$ ), $\mathrm{M}=$ divalent cation $(\mathrm{Ca}, \mathrm{Sr}, \mathrm{Ba}, \ldots)$, the disorder due to size disparity between the two A-site cations plays a role in determining and tuning their electronic properties. This is evident from the fact that different $\mathrm{Ln}_{1-\mathrm{x}} \mathrm{M}_{\mathrm{x}} \mathrm{MnO}_{3}$ perovskites with the same doping level and tolerance factor can have quite different metal-to-insulator transition temperatures [48]. As the $x$ value increases, the hole doping increases linearly. The average A cation size also changes linearly with $x$ value, but the change in disorder is non-linear, with it being minimum at $x=0$ and 1 , and maximum at $x=0.5$. The statistical variance between the distribution of the radii can be considered as the quantity to parametrize this disorder [48]. $\mathrm{La}_{1-\mathrm{x}} \mathrm{Sr}_{\mathrm{x}} \mathrm{MnO}_{3}$ is the most well studied material in this class. Here, the bond lengths and angles are lowered with an increase in $\mathrm{Sr}$ content. The effect of Sr content on lattice parameters and bond angle is depicted in Figure 2b [52]. The change here is even more dramatic compared to the prior example of switching trivalent rare-earth metals. As shown in Figure 2c [52], the $T_{N}$ first begins to decrease until a transition to a ferromagnetic insulator phase, and eventually to a ferromagnetic metal with $\mathrm{T}_{\mathrm{C}}$ of the ferromagnetic phase well above room temperature. The pressure exerted in the lattice modifies local parameters such as the $\mathrm{Mn}-\mathrm{O}$ bond length and the O-Mn-O bond angle which, in turn, affects the balance between the co-existing metallic and insulating states, and thus their CMR properties [53]. Mixed-valent perovskite manganates also exhibit many charge-ordered phases that are affected by factors such as the size of the A cations as well as isotopic and chemical substitutions [54-56]. 


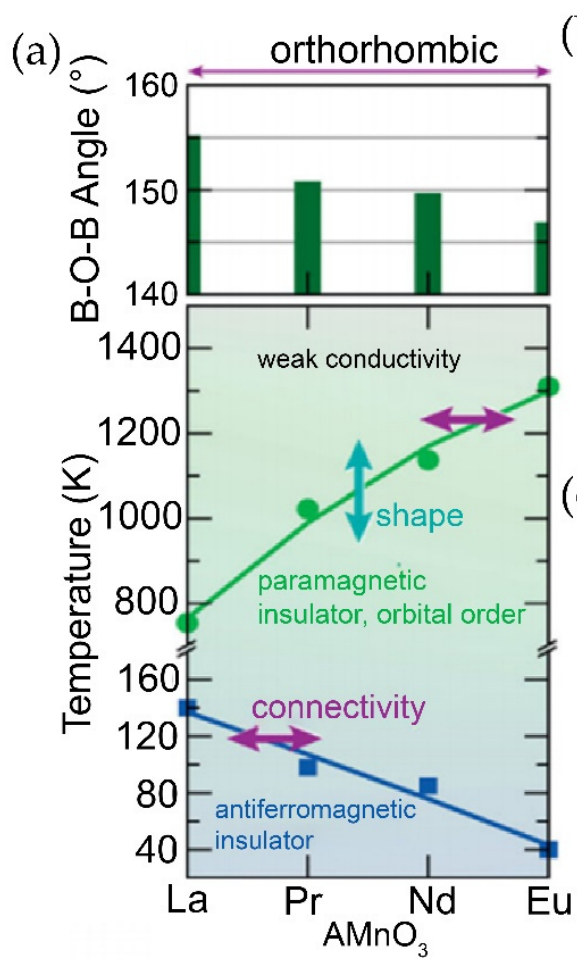

(b)
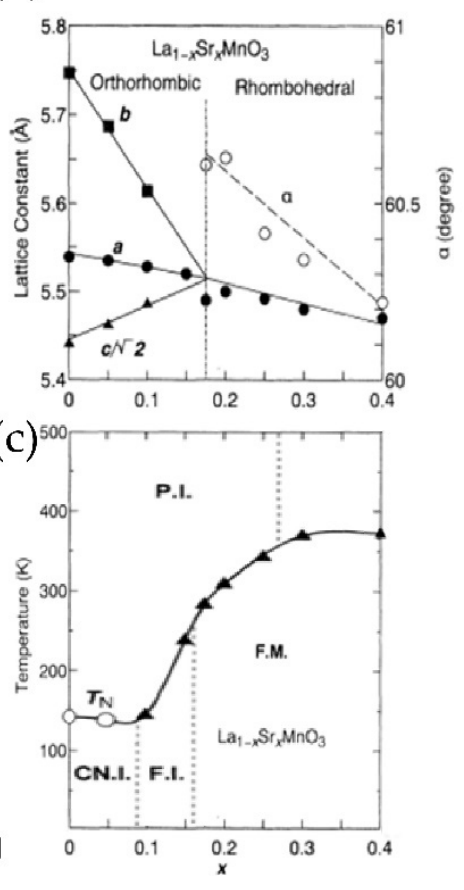

Figure 2. (a) The isovalent phase diagrams of rare-earth manganites with A-site composition exhibit changes in the octahedral connectivity (B-O-B bond angles, upper panels) and symmetry. Changes to the octahedral connectivity (horizontal arrows) affect the temperatures associated with magnetic and charge-ordering phase transitions, whereas periodic orderings of the octahedral shape and size (vertical arrows) occur at the orbital-ordering transition. Reprinted with permission from ref. [51]. Copyright ( 2022, The Materials Research Society. (b) Lattice parameters for $\mathrm{La}_{1-\mathrm{x}} \mathrm{Sr}_{\mathrm{x}} \mathrm{MnO}_{3}$ crystals at room temperature. (c) Electronic phase diagram of $\mathrm{La}_{1-x} \mathrm{Sr}_{x} \mathrm{MnO}_{3}$. Open circles and filled triangles are the Neel $\left(\mathrm{T}_{\mathrm{N}}\right)$ and Curie $\left(\mathrm{T}_{\mathrm{C}}\right)$ temperatures, respectively. The abbreviations mean paramagnetic insulator (P.I.), paramagnetic metal (P.M.), spin-canted insulator (CN.I.), ferromagnetic insulator (FI), and ferromagnetic metal (FM). Reprinted with permission from ref. [52]. Copyright 1995, American Institute of Physics.

Another well studied system is the titanate, $\mathrm{ATiO}_{3}(\mathrm{~A}=\mathrm{Ba}, \mathrm{Sr}, \mathrm{Ca})$, where the ferroelectric Curie temperature, $\mathrm{T}_{\mathrm{C}}$, was seen to be manipulatable by the size variance of the A-site cation mixture [57]. $\mathrm{Ba}_{1-\mathrm{x}} \mathrm{Sr}_{\mathrm{x}} \mathrm{TiO}_{3}$ shows a decrease in $\mathrm{T}_{\mathrm{C}}$ with an increase in $\mathrm{Sr}^{2+}$ as the smaller cation stabilizes the more symmetric cubic phase with tolerance factor decreasing from that of the ferroelectric $\mathrm{BaTiO}_{3}$, which has a tolerance factor of 1.06. However, in $\mathrm{Ba}_{1-\mathrm{x}} \mathrm{Ca}_{\mathrm{x}} \mathrm{TiO}_{3}$, the size mismatch between the A cations is bigger and only $\mathrm{x}$ up to 0.24 is stable without phase segregation. The $T_{C}$ rises to $x=0.08$ from $403 \mathrm{~K}$ to $410 \mathrm{~K}$, and then decreases to the solution limit. This behavior cannot be explained by simple size arguments, where the initial increase has been rationalized by the strain effect due to the mismatch between the two cations and the subsequent decrease due to the size effect $[49,57]$.

One of the major limitations of chemical substitution to exert chemical pressure over epitaxial strain engineering is the introduction of disorder and heterogeneity associated with chemical substitution in such films. Disorder, for example, can broaden the phase transition by hundreds of degrees [58-60]. We will discuss the epitaxial control of strain in the following sections.

\section{Epitaxial Strain Engineering}

A range of commercially available single-crystal substrates with different lattice parameters makes it possible to epitaxially grow perovskite oxide thin films with different strain states. The lattice mismatch and the strain between the substrate and the film can 
then be designed by selecting an appropriate substrate. Other considerations besides the lattice parameters are chemical and thermal expansion compatibility. The most commonly used and commercially available substrates and thin-film materials of interest are shown in the lower part of Figure 3d. Lots of materials of interest (top part of Figure 3d) can be epitaxially grown on these substrates with certain lattice mismatches.

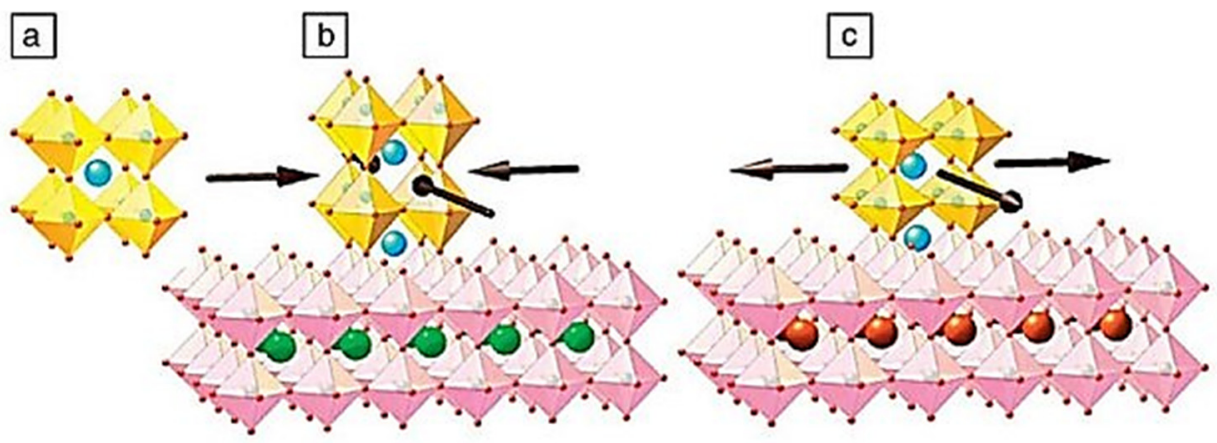

d

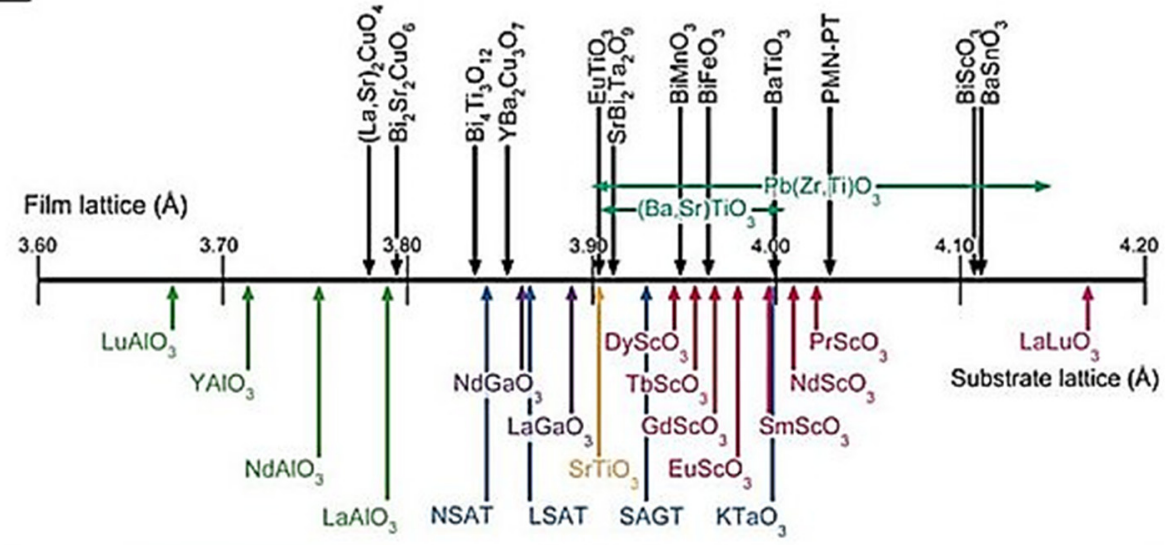

Figure 3. (a) Crystal structure of an unstrained perovskite. (b,c) Schematic illustration of an epitaxial perovskite film grown on a perovskite single-crystal substrate showing: (b) biaxiall compression, (c) biaxial tension, (d) the a-axis lattice constant in angstroms of some perovskites and perovskiterelated materials of interest. The substrates can be cubic, pseudotetragonal or pseudocubic. Reprinted with permission from ref. [9]. Copyright 2014, Cambridge University Press.

For a simple cubic lattice, the lattice mismatch, $\mathrm{f}$, between the substrate and the film can be defined as:

$$
\mathrm{f}=\frac{\mathrm{a}_{\mathrm{s}}-\mathrm{a}_{0}}{\mathrm{a}_{0}}
$$

where $\mathrm{a}_{\mathrm{s}}$ and $\mathrm{a}_{0}$ are the lattice parameters of the substrate and film in an unstrained state, respectively. In a fully strained epitaxial film, the in-plane lattice parameters of the film are constrained to the lattice of the substrate. However, as the thickness of the film increases above a critical film thickness, defects such as misfit dislocations become energetically favorable, and the lattice strain relaxes.

For isotropic films, the biaxial strain is:

$$
\varepsilon_{\mathrm{xx}}=\varepsilon_{\mathrm{yy}}=\frac{\mathrm{a}_{\|}-\mathrm{a}_{0}}{\mathrm{a}_{0}}
$$

and the out-of-plane strain is:

$$
\varepsilon_{\mathrm{zz}}=\frac{\mathrm{a}_{\perp}-\mathrm{a}_{0}}{\mathrm{a}_{0}}
$$


where $\mathrm{a}_{\|}$and $\mathrm{a}_{\perp}$ are the in-plane and out-of-plane lattice parameters of the strained epitaxial film. A substantial portion of the change in lattice parameters due to epitaxial strain is through changes in the relative magnitude of the $\left[\mathrm{BO}_{6}\right]$ octahedral rotations and the $\mathrm{B}-\mathrm{O}$ bond lengths $[51,61]$.

The strain on the film evolves with the increase in thickness of the film, as the top of the film starts to relax with dislocation defects and the strained in-plane lattice parameter starts to converge to the relaxed bulk value, deviating from that of the film-substrate interface, eventually reaching full relaxation [62]. The strain in the film leads to the storage of elastic energy and at the critical thickness, this energy equals the formation energy for misfit dislocation defects in the People-Bean model [62]. Critical thickness, therefore, is inversely correlated with the lattice mismatch [63]. However, the critical thickness can also differ depending on experimental growth conditions such as growth temperature, post growth annealing, stoichiometry, etc., due to the influence of thermal strains and defect formation. Thermal strains arise due to a mismatch between the in-plane thermal expansion coefficients between the two lattices during the cool-down process [64-66]. In cases of post-growth annealing, which are often used to decrease the number of oxygen vacancies and improve the crystallinity of the film, the detailed annealing protocol could also change the strain state in the as-deposited films. For instance, in the deposition of epitaxial films of $\mathrm{La}_{0.7} \mathrm{Sr}_{0.3} \mathrm{MnO}_{3}$ on $\mathrm{Al}_{2} \mathrm{O}_{3} / \mathrm{MgO}$ substrate-buffer platform, it has been reported that the post-growth annealing temperature beyond the deposition temperature of $\sim 900{ }^{\circ} \mathrm{C}$ could create an irreversible strain relaxation and degrade the magnetic saturation of the films. The properties of the films were only partially recovered by a second annealing step at $700{ }^{\circ} \mathrm{C}$ [67].

Vailionis et al. studied the strain accommodation in the rhombohedral $\mathrm{La}_{0.67} \mathrm{Sr}_{0.33} \mathrm{MnO}_{3}$ (LSMO) via lattice modulations and rotations $[38,68]$. Under compressive strain, LSMO has an (110) out-of-plane-oriented monoclinic unit cell with space group P21/m (No. 11), while under tensile strain it exhibits an (001) out-of-plane-oriented tetragonal unit cell with space group Cmcm (No. 63). Under compressive strain, out-of-phase octahedral rotation around the (001) direction occurs, while under tensile strain these rotations are absent. The octahedra are rotated in phase around the (100)-axis of the pseudocubic unit cell and out of phase around the (010) direction in both cases (Figure $4 a-d)$. The additional strain along the (100)-direction is accommodated by periodic lattice modulations, as shown in Figure $4 \mathrm{f}$. The changes in octahedral rotations owing to stress and the dissimilar in-plane rotational patterns affect the in-plane magnetic anisotropy in LSMO films. Similar results were seen for the orthorhombic $\mathrm{SrRuO}_{3}$, and the authors argued that this could be extrapolated to other rhombohedral and orthorhombic perovskite oxides [38]. Strain accommodation via similar lattice modulations has also been experimentally observed by high-resolution transmission electron microscopy in epitaxial $\mathrm{YBa}_{2} \mathrm{Cu}_{3} \mathrm{O}_{7-\delta}$ with the presence of twin boundaries and intergrowths $[69,70]$. High-resolution transmission electron microscopy has emerged as a powerful tool towards enabling the direct observation of such structural changes [71]. In ultrathin $\mathrm{La}_{2 / 3} \mathrm{Sr}_{1 / 3} \mathrm{MnO}_{3}$ films grown on $\mathrm{NdGaO}_{3}$ substrates, strong oxygen octahedral coupling is found to transfer the octahedral rotation in the perovskite substrate to the perovskite thin film near the interface [72]. An unexpected realignment of the magnetic easy axis along the short axis of the unit cell as well as the presence of a giant anisotropic transport in these ultrathin $\mathrm{La}_{2 / 3} \mathrm{Sr}_{1 / 3} \mathrm{MnO}_{3} / \mathrm{NdGaO}_{3}$ films was observed. Similar control over octahedral tilts was also demonstrated in $\mathrm{SrRuO}_{3}$ by using a 0-4 unit cell thick $\mathrm{Ca}_{0.5} \mathrm{Sr}_{0.5} \mathrm{TiO}_{3}$ buffer layer on $\mathrm{GdScO}_{3}$ substrates [73]. The $\mathrm{Ru}-\mathrm{O}-\mathrm{Ti}$ and the $\mathrm{Ru}-\mathrm{O}-\mathrm{Ru}$ bond angles at the interface could be tuned via changing the thickness of the buffer layer, along with affecting magnetic anisotropy in the entire $\mathrm{SrRuO}_{3}$ layer. 


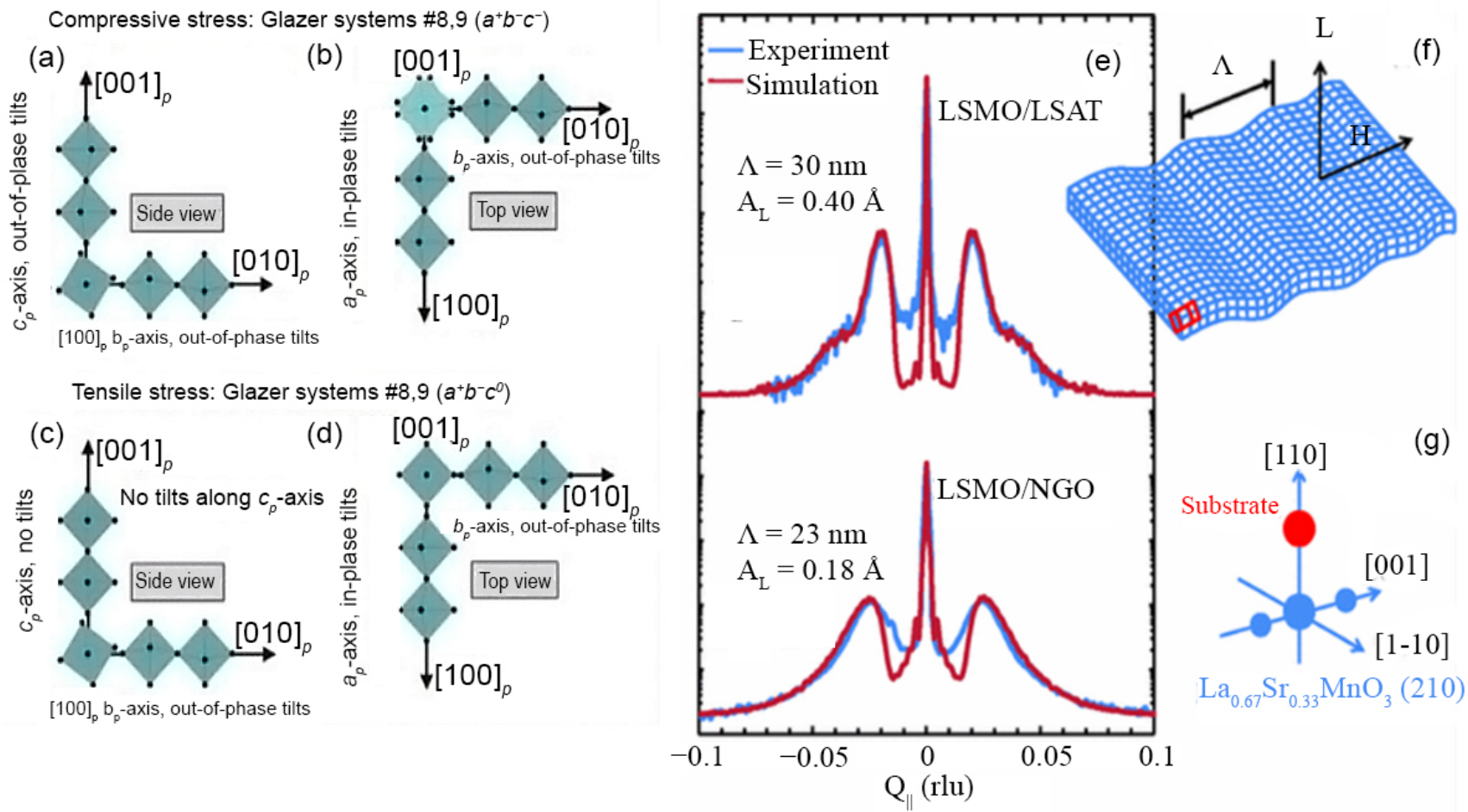

Figure 4. Schematic representation of octahedral rotational patterns in $\mathrm{La}_{0.67} \mathrm{Sr}_{0.33} \mathrm{MnO}_{3}$. (a,b) Under compressive stress. (c,d) Under tensile stress. $(\mathbf{a}, \mathbf{c})$ are the side view and $(\mathbf{b}, \mathbf{d})$ are the top view of the unit cells. Reprinted with permission from ref. [68]. Copyright 2015, Elsevier Ltd. Lattice modulations: (e) Observed (blue) and simulated (red) XRD profiles around LSMO (220) reflections for films grown on ( $\mathrm{La}, \mathrm{Sr})(\mathrm{Al}, \mathrm{Ta}) \mathrm{O}_{3}$ (LSAT) and $\mathrm{NdGaO}_{3}$ (NGO) substrates. (f) Schematic drawing of the lattice modulations used in calculations. (g) Schematic picture of a reciprocal space showing the substrate peak (red) together with the LSMO (220) peak and its first-order satellites (blue). Here, $\mathrm{Q}_{\|}=4 \pi \sin (\theta / \lambda)$, where $\theta$ is the Bragg angle and $\lambda=1.540598 \AA$. Reprinted with permission from ref. [38]. Copyright 2011, American Physical Society.

In (001) LSMO, the resistivity of thin films has been shown to be controlled via epitaxial strain. The effect on the temperature dependence of resistivity can be seen in Figure 5a [30]. Metal-to-insulator transition can be lowered considerably by using substrates that can lead to a higher tensile strain. This can be clearly seen from a systematic comparison of the resistivity vs. temperature characteristics of films on different substrates such as $\mathrm{SrTiO}_{3}(0.5 \%), \mathrm{DyScO}_{3}(1.6 \%) \mathrm{GdScO}_{3}(2.3 \%), \mathrm{SmScO}_{3}(2.7 \%)$ and $\mathrm{NdScO}_{3}(3.2 \%)$. The Curie temperature and magnetization were also seen to be dependent on substrate choice (Figure 5b). In accordance with theoretical predictions by Mills et al. [74], a best-fit plane of the Curie temperature's dependence on the bulk compressive strain $\varepsilon_{\mathrm{B}}$ (which tends to increase electron hopping probability and reduce the effects of electron-phonon coupling) and biaxial distortion $\varepsilon^{*}$ (which increases the Jahn-Teller splitting in the $e_{g}$ orbitals and acts only to reduce $\mathrm{T}_{\mathrm{C}}$ ) is shown in Figure $5 \mathrm{c}$.

Interestingly, in lightly doped manganites, the in-plane compressive strain has been found to increase the $\mathrm{T}_{\mathrm{C}}$ significantly and produce metal-insulator-transition (MIT) in the compounds that are supposed to be ferromagnetic insulators (FMI) [60]. For example, Bulk $\mathrm{La}_{0.9} \mathrm{Sr}_{0.1} \mathrm{MnO}_{3}$ is a ferromagnetic insulator with a Curie temperature $\left(\mathrm{T}_{\mathrm{C}}\right)$ of $145 \mathrm{~K}$. When grown epitaxially on $\mathrm{LAO}$, thinner $\mathrm{La}_{0.9} \mathrm{Sr}_{0.1} \mathrm{MnO}_{3}(\sim 15 \mathrm{~nm})$ films are metallic with a greatly enhanced $\mathrm{T}_{\mathrm{C}}$, which is $97 \mathrm{~K}$ higher than the bulk value. In-plane compressive strain $(-1.5 \%)$ was reported to be partially responsible for the $\mathrm{T}_{\mathrm{C}}$ enhancement. Strain-induced stoichiometry modification also plays a role in modulating the $\mathrm{T}_{\mathrm{C}}$ and strain relaxation in these thin films, accommodated both by misfit dislocations and La deficiency. 

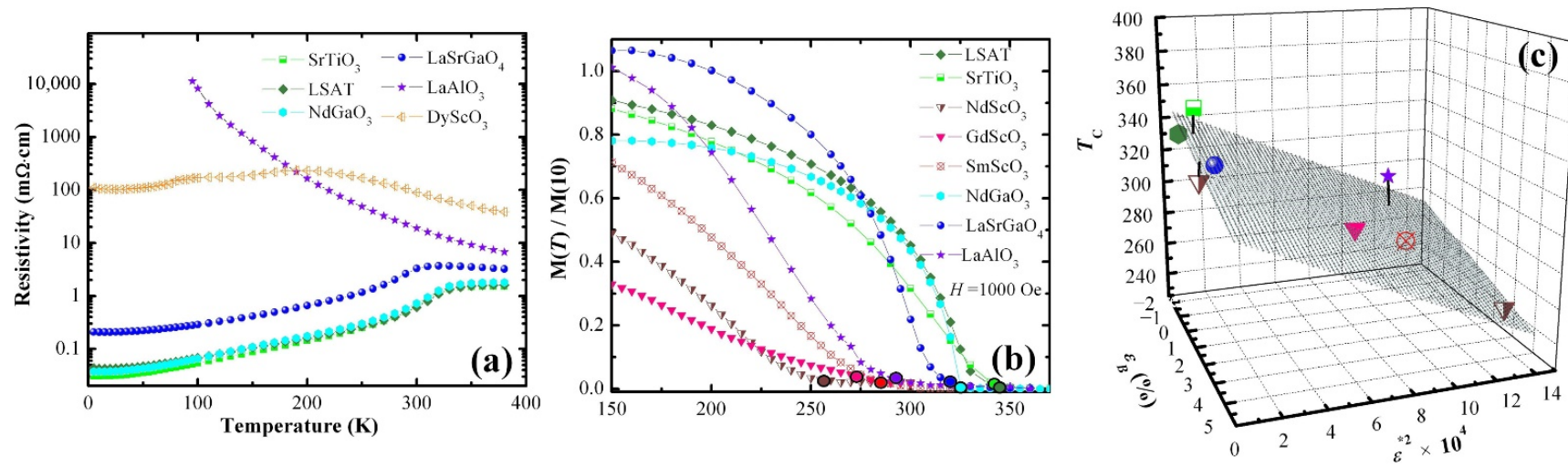

Figure 5. (a) Resistivity vs. temperature behavior, at zero applied magnetic field, of $22 \mathrm{~nm}$ thick $\mathrm{La}_{0.7} \mathrm{Sr}_{0.3} \mathrm{MnO}_{3}$ films on different substrates (10 nm thick on $\mathrm{NdScO}_{3}$ ). (b) The temperature dependence of the magnetization normalized at $10 \mathrm{~K}$ of samples cooled in a 1000 Oe field of $H=1000$ Oe. Circles indicate the Curie temperature, $\mathrm{T}_{\mathrm{C}}$. (c) The Curie temperature $\mathrm{T}_{\mathrm{C}}$ vs. the $\varepsilon_{\mathrm{B}}$ and $\varepsilon^{*}$ strains. The best fit plane to the data is also shown. Reprinted with permission from ref. [30]. Copyright 2009, American Institute of Physics.

The opposite effect of compressive in-plane strain on optimally doped and lightly doped manganites is not surprising. In optimally doped manganites, the in-plane compressive strain induces the change in the $\mathrm{O}-\mathrm{Mn}-\mathrm{O}$ bond angle and length away from the ideal case. This, therefore, reduces $\mathrm{T}_{\mathrm{C}}$ and MIT. It is noted that this strain in lightly doped manganites induces oxygen octahedral tilt and straightens the out-of-plane $\mathrm{O}-\mathrm{Mn}-\mathrm{O}$ chain which promotes MIT.

Lattice strain has also been implicated in oxygen vacancy formation which can lead to radical changes in the physical properties of these films. For instance, oxygen vacancies may act as pinning sites for ferroelectric and magnetic domain wall movements, create structural disorder and introduce electronic defects [75-77]. In the prototypical ferroelectric perovskite system, $\mathrm{PbTiO}_{3}$, ab initio study showed that oxygen vacancies that act as strong domain pinning centers can be modulated to a non-pinning center via compressive misfit strain by changing the formation energies of the various types of oxygen vacancies, as shown in Figure 6a,b [78]. Ferroelectric distortion stabilized in $\mathrm{SrTiO}_{3}$ by epitaxial strain has also been shown to promote the formation of oxygen vacancies [79]. In half-doped manganite, $\mathrm{La}_{0.5} \mathrm{Sr}_{0.5} \mathrm{MnO}_{3}$, the epitaxial strain was shown to modulate ferromagnetic and antiferromagnetic phase proportions by manipulating the oxygen nonstochiometry as evidenced by the change in $\mathrm{Mn}^{3+}$ and $\mathrm{Mn}^{4+}$ ratio with the increase in thickness (Figure 6d). This was seen to lead to depressed magnetization and enhanced exchange bias (Figure 6c) [80]. In $\mathrm{La}_{0.67} \mathrm{Ca}_{0.33} \mathrm{MnO}_{3}$, the epitaxial strain was implicated in the formation of a dead layer near the interface with a higher concentration of oxygen vacancies with reduced Mn valence and the unidirectional displacement of $\mathrm{Mn}$ ions [81].

The tuning of $\mathrm{T}_{\mathrm{C}}$ in ferroelectric systems via epitaxial strain can be well illustrated in the titanates. The much enhanced ferroelectric property is most explicitly demonstrated by the case of $\mathrm{SrTiO}_{3}$, which is normally not ferroelectric at any temperature without any lattice strain. However, when $\mathrm{SrTiO}_{3}$ is grown epitaxially on $\mathrm{DySCO}_{3}$, with an inplane tensile strain of $\sim 0.94 \%$, fully strained $\mathrm{SrTiO}_{3}$ film shows a $\mathrm{T}_{\mathrm{C}}$ as high as $293 \mathrm{~K}$ [13]. This strained $\mathrm{SrTiO}_{3}$ film was later demonstrated to be an orthorhombic phase [82], and showed an antiferrodistortive phase transition that exhibited ferroelastic-ferroelectric multiferroicity [83]. The strain vs. Curie temperature phase diagram of $\mathrm{SrTiO}_{3}$ predicted from thermodynamic principles using a Landau-Ginsburg-Devonshire-type theory by Persev et al. is shown in Figure 7a. It illustrates the complex interconnection between the Curie temperature and the lattice strain $[13,84]$. 

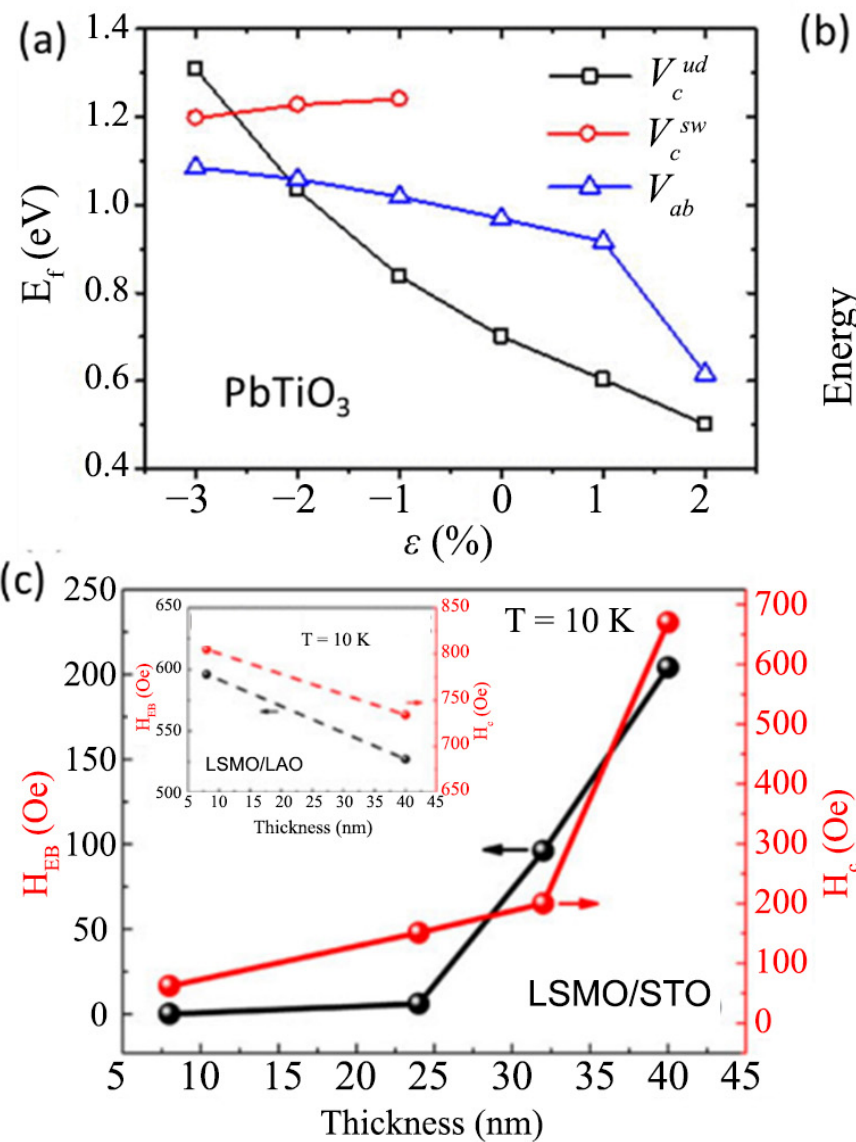

(b)
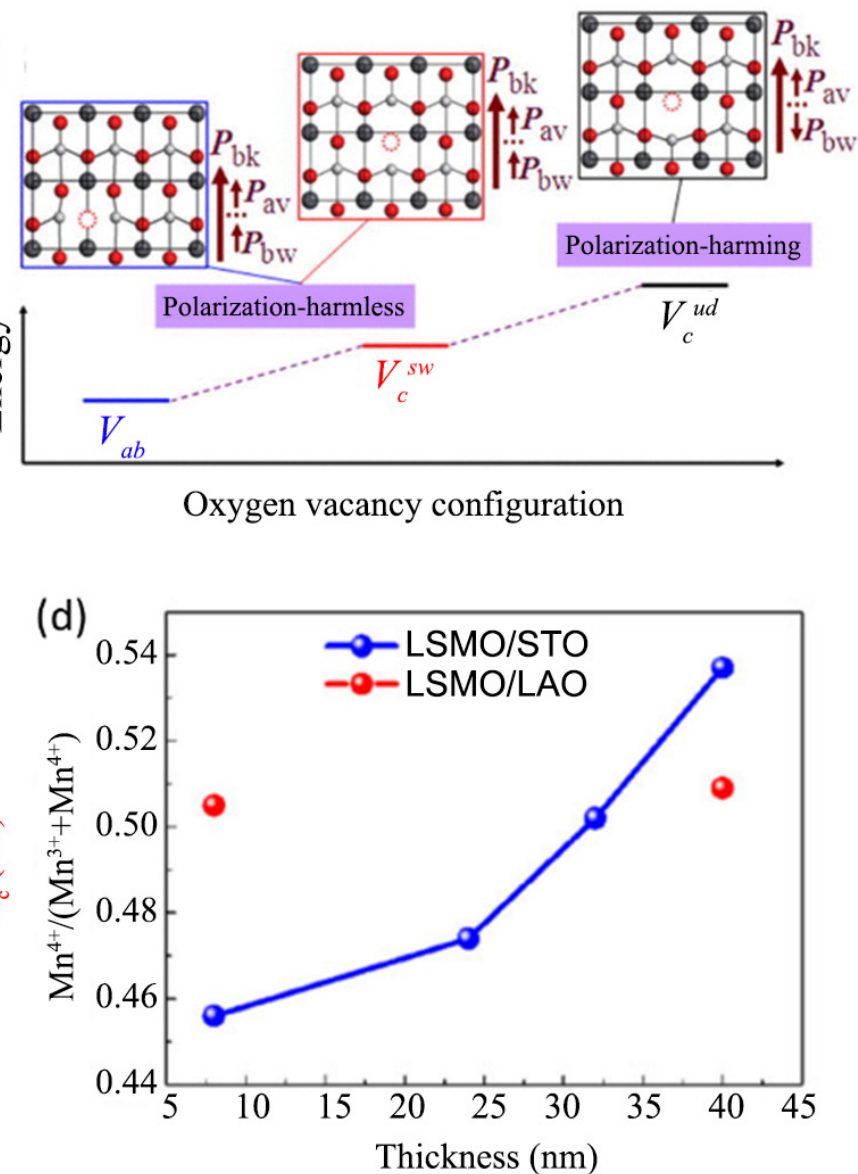

Figure 6. (a) Formation energies $\left(\mathrm{E}_{\mathrm{f}}\right)$ of different types of oxygen vacancy under different strains. The black, red, and blue symbols represent $E_{f}$ of $V_{c}^{u d}, V_{c}^{s w}$, and $V_{a b}$, respectively. The formation of the "up-down" pattern along the $x$-axis causes the sudden decrease in energy of $V_{a b}$ when $2 \%$ tensile strain is applied. (b) The relative energy stabilities and the polarization patterns of different oxygen vacancy configurations in 3\% compressive-strained $\mathrm{PbTiO}_{3}$. Reprinted with permission from ref. [65]. Copyright 2013, American Institute of Physics. (c) Thickness dependence of $\mathrm{H}_{\mathrm{C}}$ (right axis) and $\mathrm{H}_{\mathrm{EB}}$ (left axis). For comparison, inset shows $\mathrm{H}_{\mathrm{C}}$ and $\mathrm{H}_{\mathrm{EB}}$ of $\mathrm{La}_{0.5} \mathrm{Sr}_{0.5} \mathrm{MnO}_{3}$ films grown on the $\mathrm{LaAlO}_{3}$ substrate with the thickness of 8 and $40 \mathrm{~nm}$ (d) The thickness dependence of $\mathrm{Mn}^{4+} /\left(\mathrm{Mn}^{3+}+\mathrm{Mn}^{4+}\right)$ ratio in $\mathrm{La}_{0.5} \mathrm{Sr}_{0.5} \mathrm{MnO}_{3}$ films grown on the $\mathrm{SrTiO}_{3}$ substrate. The red dots correspond to the data of $\mathrm{La}_{0.5} \mathrm{Sr}_{0.5} \mathrm{MnO}_{3}$ films grown on the $\mathrm{LaAlO}_{3}$ substrate for comparison. Reprinted with permission from ref. [67]. Copyright 2016, Materials Research Society.

The coupling between the lattice strain and the ferroelectric properties such as Curie temperature is common in perovskite metal oxides. For instance, the Curie temperature and the ferroelectric polarization of the classical ferroelectric perovskites $\mathrm{BaTiO}_{3}$ and $\mathrm{PbTiO}_{3}$ can also be influenced by lattice strain. $\mathrm{BaTiO}_{3}$ thin films coherently grown on $\mathrm{GdScO}_{3}$ and $\mathrm{DyScO}_{3}$ substrates with a misfit strain of about $-1.0 \%$ and $-1.7 \%$, respectively, show a large increase in ferroelectric transition temperature with a $\mathrm{T}_{\mathrm{C}} 400{ }^{\circ} \mathrm{C}$ on $\mathrm{GdScO}_{3}$ and $540{ }^{\circ} \mathrm{C}$ on $\mathrm{DyScO}_{3}$. In comparison, the $\mathrm{T}_{\mathrm{C}}$ is only $120{ }^{\circ} \mathrm{C}$ for bulk $\mathrm{BaTiO}_{3}$. It was also observed that the strained thin film had a remnant polarization $250 \%$ higher than bulk $\mathrm{BaTiO}_{3}$ single crystals (Figure 7b) [11]. These results are comparable to unstrained $\mathrm{Pb}\left(\mathrm{Zr}_{\mathrm{x}} \mathrm{Ti}_{1-\mathrm{x}}\right) \mathrm{O}_{3}$, but with a lead-free composition, which is preferable due to environmental and human health implications of the processing and disposal of the toxic element. Theoretical studies also suggest that there are temperature and strain regions, in particular, under tensile strain, where the system decomposes into multi-domain structures [85-87]. Despite both $\mathrm{BaTiO}_{3}$ and $\mathrm{PbTiO}_{3}$ being titanates, the primary drivers of ferroelectric polarization differ. For 
$\mathrm{BaTiO}_{3}$, the polarization arises from the off-centering of the $\mathrm{Ti}^{+4}$ cation, while the $6 \mathrm{~s}^{2}$ lone pair on $\mathrm{Pb}^{2+}$ in $\mathrm{PbTiO}_{3}$ is stereoactive and contributes to the ferroelectric polarization too. Different approximations and assumptions about domain configurations in thermodynamic analysis and phase-field simulations of strain-phase diagrams of $\mathrm{PbTiO}_{3}$ lead to markedly different phase diagrams, as shown in Figure 8. All the diagrams involve the paraelectric phase, the tetragonal c-phase, and are under the assumption of a single-domain film. The orthorhombic aa-phase exists at higher in-plane strains with a "monoclinic gap" $r$ phase between the tetragonal and orthorhombic phases (Figure 8a). However, real films always have more than one type of domain and extended phase diagrams that account for two-dimensional domains are subsequently derived from thermodynamic calculations of Pertsev et al. (Figure 8b,c) [88,89]. Subsequently, phase-field models, which could predict multi-domain states without making assumptions about domain wall orientation, were used to derive the three-dimensional phase diagram shown in Figure 8d. Experimental and theoretical calculations concur that the $\mathrm{T}_{\mathrm{C}}$ can be increased via both tensile and compressive strains. It is noted that the $T_{C}$ is also evidently affected by the film thickness. The increase in $T_{C}$ with film thickness indicates that the ferroelectric property is further affected by grain size in addition to the lattice strain $[90,91]$.

(a)

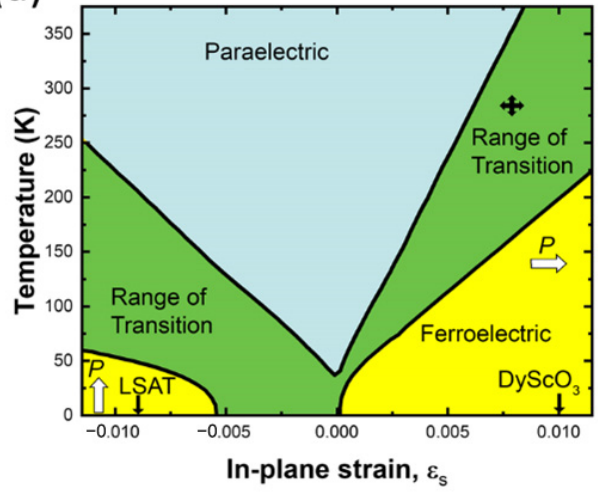

(b)

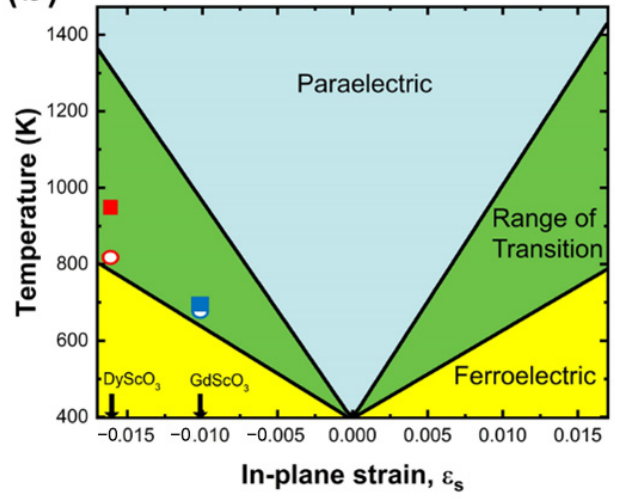

Figure 7. (a) Expected shift in $\mathrm{T}_{\mathrm{C}}$ of (100) $\mathrm{SrTiO}_{3}$ with biaxial in-plane strain, based on thermodynamic analysis. The arrows indicate the predicted direction of the polarization for strained $\mathrm{SrTiO}_{3}$ : in-plane for biaxial tensile strain and out-of-plane for biaxial compressive strain. The $\varepsilon_{\mathrm{s}}$ values for $\mathrm{SrTiO}_{3}$ fully constrained (commensurate) to the lattice constants of LSAT and (110) $\mathrm{DyScO}_{3}$ substrates are indicated by the positions of the corresponding arrows. The cross shows the observed $\mathrm{T}_{\mathrm{C}}$ shift of a $500 \AA$ thick $\mathrm{SrTiO}_{3}$ film epitaxially grown on (110) $\mathrm{DyScO}_{3}$. Adapted with permission from ref. [13]. Copyright 2004, Springer Nature. (b) Expected $\mathrm{T}_{\mathrm{C}}$ of (001) $\mathrm{BaTiO}_{3}$ under biaxial in-plane strain $\left(\varepsilon_{\mathrm{s}}\right)$, based on thermodynamic analysis. The green region represents the range (error bars) in the predicted $\mathrm{T}_{\mathrm{C}}$ resulting from the spread in reported property coefficients for $\mathrm{BaTiO}_{3}$ that enter into the thermodynamic analysis. The data points show the observed $\varepsilon_{\mathrm{s}}$ and $\mathrm{T}_{\mathrm{C}}$ values of coherent $\mathrm{BaTiO}_{3}$ films grown by $\mathrm{MBE}$ on $\mathrm{GdScO}_{3}$ (blue circle) and $\mathrm{DyScO}_{3}$ (red circle) substrates and by PLD on $\mathrm{GdScO}_{3}$ (blue square) and $\mathrm{DyScO}_{3}$ (red square) substrates. Adapted with permission from ref. [11]. Copyright 2004, AAAS. 
(a)

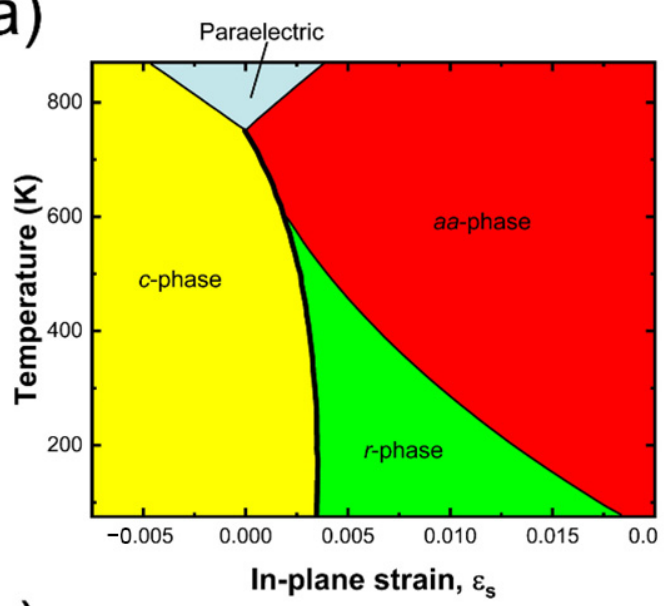

(c)

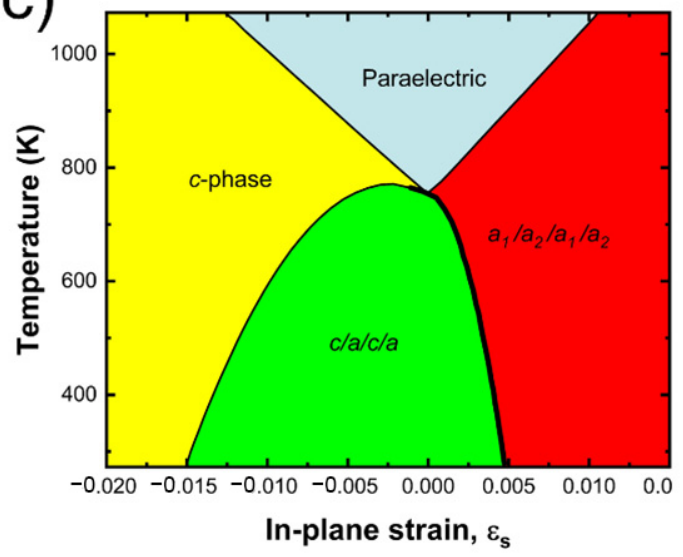

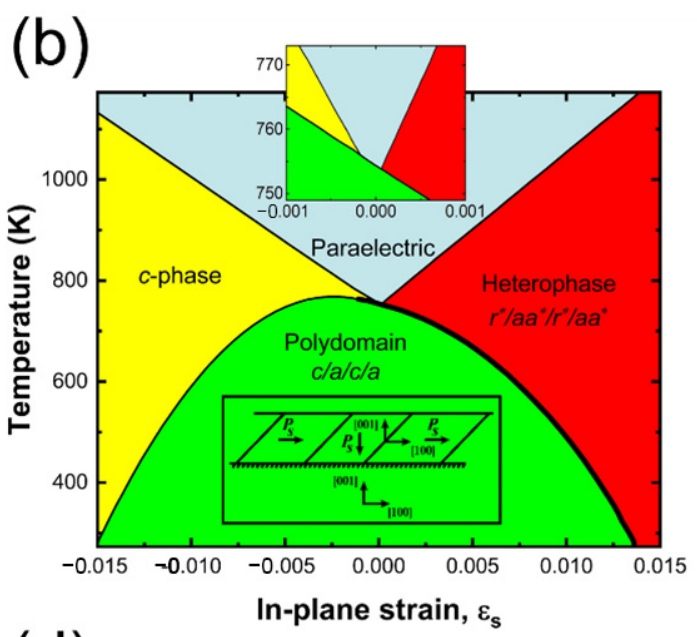

(d)

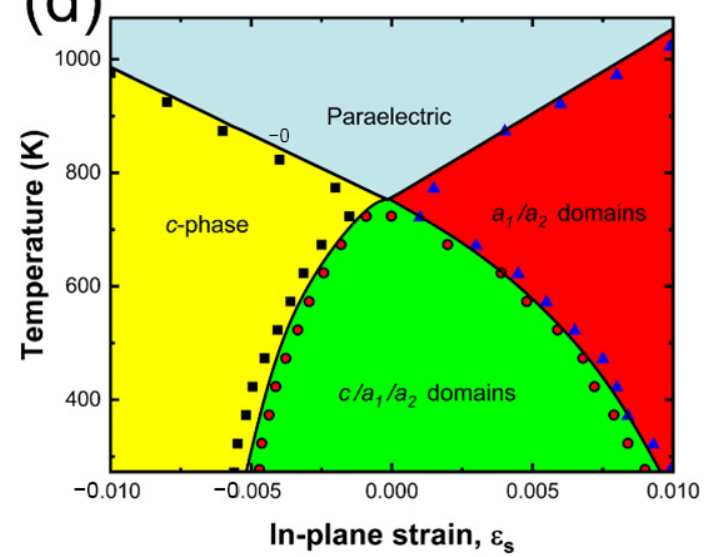

Figure 8. Four strain-phase diagrams of (001) pseudocubic-oriented $\mathrm{PbTiO}_{3}$ calculated using thermodynamic analysis or phase-field simulations and different assumptions of the ferroelectric domain states. (a) Single domain for all ferroelectric states. Adapted with permission from ref. [92]. Copyright 1998, American Physical Society. (b) Either single- or double-domain states with domain-wall orientations restricted to be $45^{\circ}$ from the film/substrate interface. Adapted with permission from ref. [88]. Copyright 2000, American Physical Society. (c) Single- or double-domain states with domain-wall orientations restricted to be either $45^{\circ}$ or $90^{\circ}$ from the film/substrate interface. Adapted with permission from ref. [89]. Copyright 2001, American Physical Society. First-order phase transitions are shown by thick lines in (a-c). (d) From three-dimensional phase-field simulations that automatically predict the possible multidomain states without assuming the domain-wall orientations. Adapted with permission from ref. [93]. Copyright 2008, American Institute of Physics.

\section{Superlattices}

In layered structures and superlattices, strain relaxation behaviors are different from single-layer systems. The lattice mismatch between the layers and their thicknesses can all contribute to the strain state of the whole structure. For instance, strain engineering of superlattices such as $\mathrm{BaTiO}_{3} / \mathrm{SrRuO}_{3}$ can be achieved by choosing suitable substrates and controlling the thickness of each component layer [63]. One of the remarkable examples of superlattices and their unique interplay with strain is seen in the system of $\left(\mathrm{SrTiO}_{3}\right) /\left(\mathrm{BaTiO}_{3}\right) /\left(\mathrm{CaTiO}_{3}\right)$, where the $\mathrm{BaTiO}_{3}$ layer shows strain-induced ferroelectric polarization with $50 \%$ enhancement of the superlattice global polarization compared to a pure $\mathrm{BaTiO}_{3}$ layer grown similarly (Figure 9) [94]. The $\mathrm{BaTiO}_{3}$ layer remains fully strained as long as the number of unit cells does not exceed that of the combined $\mathrm{SrTiO}_{3}$ and $\mathrm{CaTiO}_{3}$. Figure $9 \mathrm{c}$ shows how the lattice parameter of the superlattice shifts as a function of the stacking sequence. Their polarization is depicted in Figure $9 \mathrm{~d}$. Polarization is strongest when the $\mathrm{BaTiO}_{3}$ layer is thin enough to be fully strained but thick enough 
to contain enough non-interfacial $\mathrm{TiO}_{6}$ octahedra. The advantage of such superlattices is the possibility of breaking inversion symmetry that persists with most two-component or symmetric superlattices [95], and provides additional freedom in tuning the average lattice parameter [94]. The interrogation of $\varepsilon(E)$ curves shown in Figure 9b illustrates asymmetric response due to compositionally broken symmetry.
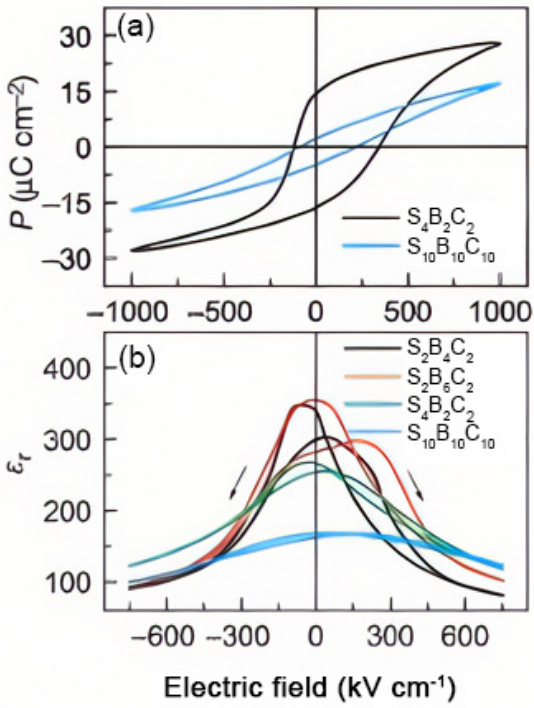
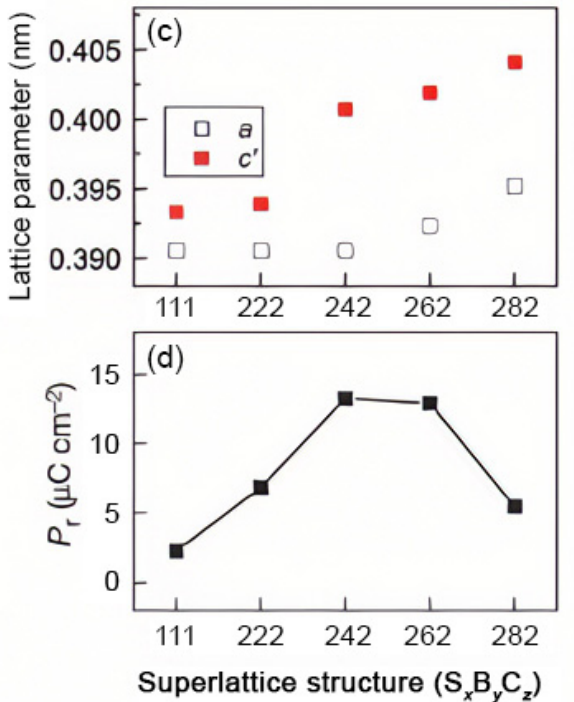

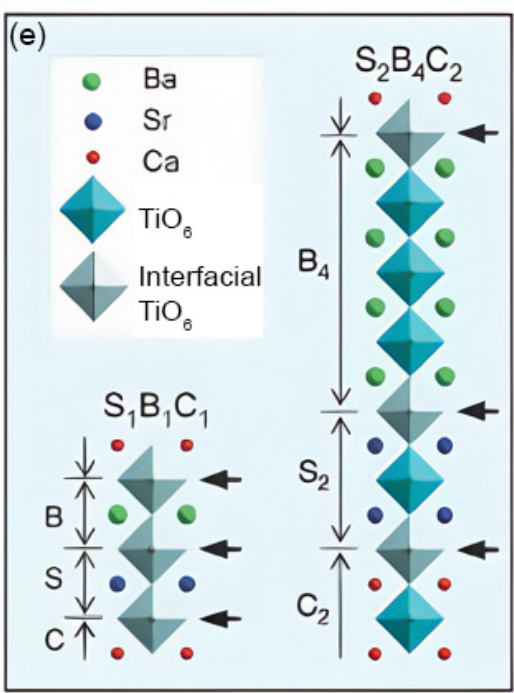

Figure 9. (a) $P(E)$ curves of $\mathrm{S}_{2} \mathrm{~B}_{4} \mathrm{C}_{2}\left(P_{\mathrm{r}} \approx 16.5 \mu \mathrm{Ccm}^{-2}\right)$ and $\mathrm{S}_{10} \mathrm{~B}_{10} \mathrm{C}_{10}\left(P_{\mathrm{r}} \approx 3.5 \mu \mathrm{Ccm}^{-2}\right)$ at $1000 \mathrm{kV} \mathrm{cm}^{-1}$. (Note that this electric field is higher than that applied to measure the polarization of the $\mathrm{BaTiO}_{3}$ film, whose polarization is near saturation at $400 \mathrm{kV} \mathrm{cm}$, whereas the $\mathrm{S}_{2} \mathrm{~B}_{4} \mathrm{C}_{2}$ requires a higher electric field $\left.\left(\sim 700 \mathrm{kV} \mathrm{cm}^{-1}\right)\right)$. (b), $\varepsilon(E)$ curves of $\mathrm{S}_{2} \mathrm{~B}_{4} \mathrm{C}_{2}$ (black line), $\mathrm{S}_{2} \mathrm{~B}_{6} \mathrm{C}_{2}$ (red line), $\mathrm{S}_{4} \mathrm{~B}_{2} \mathrm{C}_{2}$ (green line) and $\mathrm{S}_{10} \mathrm{~B}_{10} \mathrm{C}_{10}$ (light blue line) showing differing degrees of asymmetry. (c) In-plane (open squares) and out-of-plane (filled squares) lattice parameters of various superlattices. $c^{\prime}$ corresponds to the supercell $c$ divided by the number of constituent perovskites in a supercell. (d), $P_{\mathrm{r}}$ values from $E= \pm 750 \mathrm{kV} \mathrm{cm}^{-1}$ loops. The partially relaxed $\mathrm{S}_{2} \mathrm{~B}_{8} \mathrm{C}_{2}$ structure was measured with $E= \pm 650 \mathrm{kV} \mathrm{cm}^{-1}$ because of its lower breakdown strength. (e) Diagrams of supercells showing the different local environments possible for the $\mathrm{TiO}_{6}$-octahedra (bound by the same or different A-site cations). Heterointerfacial $\mathrm{TiO}_{6}$ octahedra are shaded in grey and indicated by solid black arrows. Reprinted with permission from ref. [94]. Copyright 2010, Springer Nature.

\section{Vertically Aligned Nanocomposites}

As discussed above, epitaxial strain provides an alternative pathway to chemical doping for manipulating the physical properties of a range of perovskite metal oxide films. Experimental results have indeed demonstrated that much improved physical properties and/or emergent behaviors could be accomplished by growing lattice-strained epitaxial perovskite metal oxide thin films [11,13,94,96-98]. However, enhanced functionalities are typically achieved in such epitaxial metal oxide films with a thickness of less than a few tens of nanometers at which the lattice strain could be maintained [11,13,97-99].

For many technological applications, lattice-strained thick epitaxial perovskite metal oxide films (in the range of $\sim \mu \mathrm{m}$ or above) are needed. In a conventional lattice strain framework, heteroepitaxial strain resulting from the lattice mismatch between the film and the substrate exists only below a critical film thickness. In other words, films are strained to the substrate lattice up to a critical thickness, $h_{c}$. Above $h_{c}$, the strain energy becomes so large that the nucleation of misfit dislocations at the interface is then energetically favorable to relieve the strain. The critical thickness, $\mathrm{h}_{\mathrm{c}}$, at which the formation of dislocations becomes favorable, can be expressed as:

$$
h_{c}=\frac{b}{4 \pi f(1+v)}\left[\ln \left(\frac{h_{c}}{b}\right)+1\right]
$$


where $\mathrm{v}$ is the Poisson ratio, $\mathrm{b}$ is the magnitude of the Burgers vector, and $\mathrm{f}$ is the lattice mismatch between the film and the substrate. As can be seen from Equation (5), reducing the lattice mismatch could circumvent the upper limit of critical film thickness to some extent.

Great success in the lattice strain of much thicker films has been demonstrated in the vertically aligned nanocomposite, where the lattice strain is predominantly controlled by the vertical interface between the two individual constituents instead of the lateral interface between the film and the substrate. As shown in Figure 10a, vertically aligned nanocomposite film is composed of a regularly arranged $A: B$ network from an array of vertically aligned nanopillar-like material $A$ with a feature size $d$ entrenched in a matrix of material $B$. Since both constituents $A$ and $B$ are laterally coupled across the vertical interface through the whole film thickness, as shown in Figure 10b, the vertical strain can exist in thick films. For example, lead-free, self-assembled $\mathrm{BaTiO}_{3}: \mathrm{Sm}_{2} \mathrm{O}_{3}$ nanocomposite films (up to $1.25 \mu \mathrm{m}$ thick) were grown that exhibited tetragonality up to at least $800{ }^{\circ} \mathrm{C}$ and strong remanent polarization to at least $330{ }^{\circ} \mathrm{C}$ [100]. Similar nanocomposites, such as $\mathrm{Ba}_{0,6} \mathrm{Sr}_{0.4} \mathrm{TiO}_{3}: \mathrm{Sm}_{2} \mathrm{O}_{3}$, with film thickness in the range of $1.0 \mu \mathrm{m}$ were also demonstrated that showed tetragonality up to at least $400{ }^{\circ} \mathrm{C}$ [101].

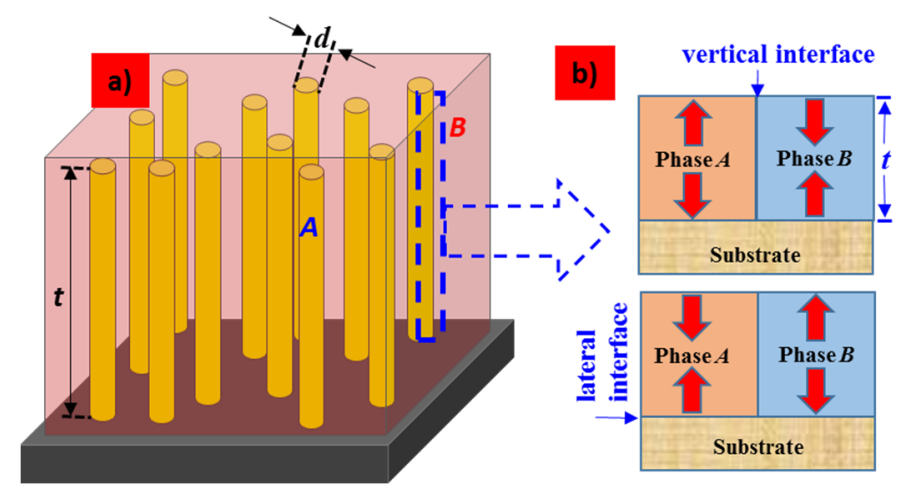

Figure 10. Schematic illustration (not to scale) of a vertically aligned epitaxial nanocomposite film on a substrate: (a) an array of vertically aligned nanopillar-like material $A$ with a feature size $d$ entrenched in a matrix of material $B$ and (b) the lattice-strain interactions across the vertical interface. For simplicity, both phases are shown to be strained equally, but in different strain states (compression or tension).

Characteristics of lateral epitaxial strain are well studied. However, the relationship between vertical strain and microstructure in vertically aligned nanocomposites is less known. It is important to know the parameters that control the vertical strain and microstructure of the nanocomposites. The final microstructure (pillar size, shape, and lateral spacing) of a vertically aligned nanocomposite film is determined by the minimization of the total free energy, which includes the elastic and interfacial energies of the system composed of the two individual phases $(A$ and $B)$ and the substrate. At the given growth conditions, both the size and volume of pillars predominantly determine the interfacial area at the vertical interface. It is accepted that the pillar size $d$, the density of the nanopillars, as well as the defects along the vertical interface determine the overall strain state of vertically aligned nanocomposites [32]. Figure 11 shows the general relationship between the vertical strain, the pillar feature size, and the volume of pillars [102]. Figure 11 also shows the general correlation among the growth temperature, pillar size, and strain state. In a system with a fixed second-phase volume, a higher growth temperature will generally produce a larger pillar size. This will result in a smaller interface area, which usually leads to a lower vertical strain. On the other hand, a lower growth temperature generally results in a smaller pillar size and larger interface area, which can lead to a larger vertical strain. In a system with a fixed pillar size, the increase in the pillar density can increase the total vertical interface area and thus lead to a larger strain. It was reported that the vertical strain in vertically aligned nanocomposites is ultimately related to the vertical interfacial area 
and interfacial dislocation density [12,32]. This can be understood by the following. In a nanocomposite with uniform nanopillars embedded in the film matrix, the total volume of nanopillar phase is $V=n \times \pi d^{2} / 4 \times h$, where $n$ is the number of nanopillars, and $h$ is the film thickness or pillar height. The total vertical surface area can be expressed as $S=n \times \pi d \times h=\pi d \times 4 V /\left(\pi d^{2}\right)=4 V / d$. Since Figure 11 shows strain $\varepsilon$ is proportional to $1 / d$ and $V$ then, ultimately, strain is directly controlled by the vertical interface area. The efficiency of the vertical interface coupling is related to the coherence of the interface.

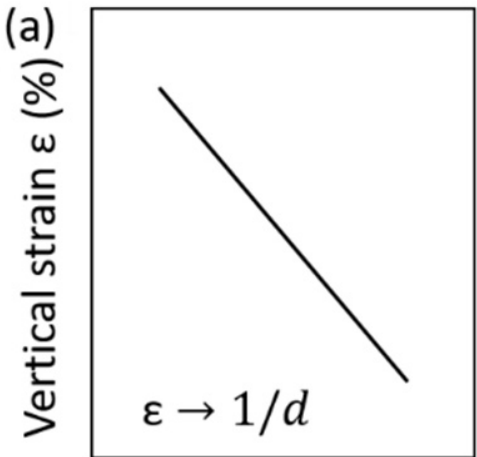

Pillar size $d$ (b)

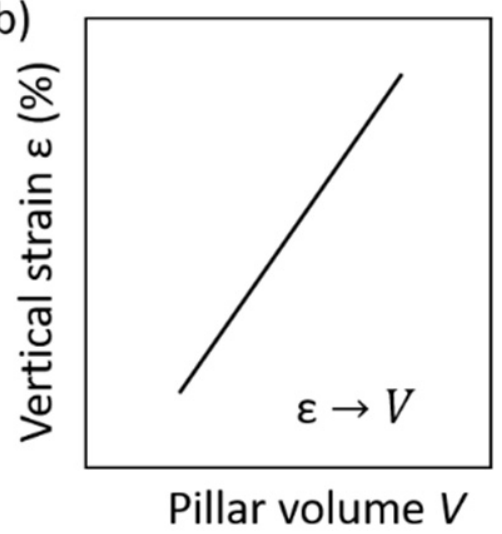

(c)

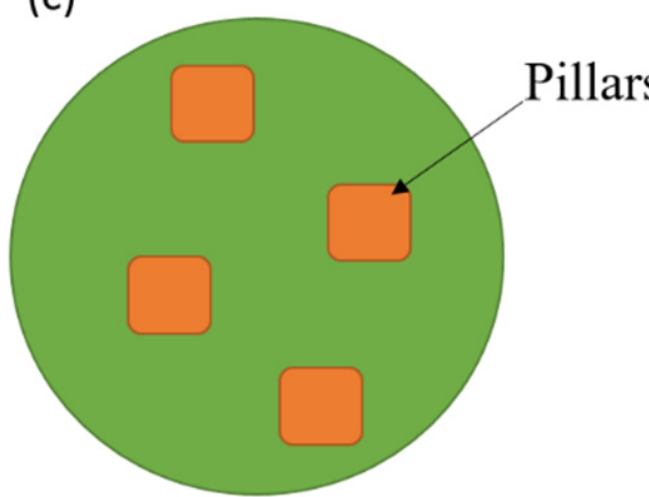

High growth temperature Big pillars, square shape Small interface area Low strain

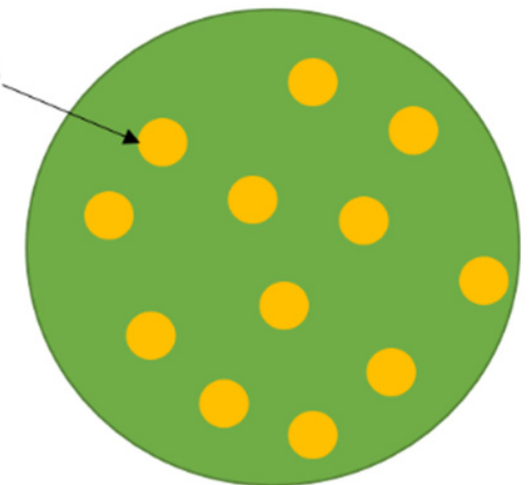

\section{Low growth temperature Small pillars, circular shape Larger interface area High strain}

Figure 11. (a) The pillar-size-dependent vertical strain in the nanocomposite film with a fixed pillar volume. In this case, $\varepsilon$ is proportional to $1 / d$. (b) Pillar-volume-dependent vertical strain in the nanocomposite film with a fixed pillar size. In this case, $\varepsilon$ is proportional to the pillar volume $V$ when $V$ is below 20-30 percent. (c) Illustrations of growth temperature, pillar size and strain state in the nanocomposites. Reprinted with permission from ref. [102]. Copyright 2021, Springer Nature.

Tables 1 and 2 have summarized some vertically aligned nanocomposite films with the inclusion of perovskite metal oxides reported in the literature [32]. For most material systems, the assembly occurs as a result of nucleation and growth, with embedded pillars of the elastically stiffer phase in the matrix of the softer phase or the perovskite oxides. Pseudospinodal decomposition is the other growth mode which can lead to a checkerboard configuration which is associated with symmetry-lifting crystal lattice rearrangement $[103,104]$. 
Table 1. Summary of vertical lattice strain reported in different material systems with direct latticematching between the constituents $A$ and $B$. For the direct lattice-matching of strained lattices, $\mathrm{m}$ lattices of phase $A$ match with $K$ lattices of phase $B$ ( $\mathrm{m}$ and $\mathrm{k}$ are positive integer numbers). The data was taken with permission from [32]. Copyright 2016, American Association for the Advancement of Science.

\begin{tabular}{cccccc}
\hline System & $\mathbf{a}_{\text {bulk }}[\AA \AA \mathbf{A}]$ & $\boldsymbol{K}$ & $|\mathbf{f}| \mathbf{[ \% ]}$ & $\left.\left|\boldsymbol{\varepsilon}_{\mathbf{z z}}\right| \mathbf{[ \%}\right]$ & Reference \\
\hline LSMO:MgO & $3.87: 4.21$ & 1 & 8.41 & 2.0 & {$[32]$} \\
LCMO:MgO & $3.86: 4.21$ & 1 & 8.67 & 2.1 & {$[105]$} \\
BFO:CFO & $3.96: 8.39$ & 2 & 5.76 & 1.0 & {$[106]$} \\
BTO:CFO & $4.04: 8.39$ & 2 & 3.76 & 1.6 & {$[107]$} \\
BFO:LSMO & $3.96: 3.87$ & 1 & 2.29 & 1.3 & {$[108]$} \\
BZO:YBCO & $11.679: 4.193$ & 3 & 7.70 & 1.0 & {$[109]$} \\
\hline
\end{tabular}

Table 2. Summary of vertical lattice strain reported in different materials systems with domainmatching between the constituents $A$ and $B$. The data was taken with permission from [32]. Copyright 2016, American Association for the Advancement of Science.

\begin{tabular}{|c|c|c|c|c|c|c|}
\hline System & $\mathrm{a}_{\text {bulk }}[\AA]$ & m & $\mathrm{m}: \mathrm{m}+1$ & $|f|[\%]$ & $\left|\varepsilon_{z z}\right|[\%]$ & Reference \\
\hline LSMO (001):ZnO (110) & $3.87: 3.24$ & 5.14 & $5: 6$ & 0.46 & $\approx 0.5,1.0$ & {$[110,111]$} \\
\hline LSMO (111):ZnO (0001) & $6.70: 5.21$ & 3.50 & $3: 4+4: 5$ & $8.5 \times 10-3$ & 0 & {$[112,113]$} \\
\hline $\mathrm{CeO}_{2}: \mathrm{LSMO}^{*}$ & $5.41: 3.87$ & 2.51 & $2: 3+3: 4$ & 0.13 & $<0.1$ & [114] \\
\hline $\mathrm{SrZrO}_{3}: \mathrm{Gd}_{2} \mathrm{O}_{3} * *$ & $4.09: 2.70$ & 1.94 & $2: 3$ & 0.98 & 0.9 & [115] \\
\hline BTO: $\mathrm{Sm}_{2} \mathrm{O}_{3}$ & 4.04:2.73 & 2.08 & $2: 3$ & 1.17 & 2.35 & [116] \\
\hline $\mathrm{BFO}: \mathrm{Sm}_{2} \mathrm{O}_{3}$ & $3.96: 2.73$ & 2.22 & $2: 3+2: 3+3: 4$ & 1.71 & $\approx 1.4$ & [110] \\
\hline STO: $\mathrm{Sm}_{2} \mathrm{O}_{3}$ & $3.905: 2.73$ & 2.32 & $2: 3+2: 3+3: 4$ & 0.31 & - & [117] \\
\hline
\end{tabular}

* The calculated $\mathrm{m}$ value is 2.51 for $\mathrm{CeO}_{2}: \mathrm{LSMO}$; therefore, $\mathrm{m}$ can be valued as 2 or 3 . Therefore, both 2:3 and 3:4 matchings exist and align alternatively (50\%:50\%). In the STO: $\mathrm{Sm}_{2} \mathrm{O}_{3}$ system, $\mathrm{m}$ is 2.32 . $\mathrm{m}$ can be either 2 or 3. Both 2:3 and 3:4 matchings exist with a frequency of $66 \% 2: 3$ and $34 \% 3: 4$. In the $\mathrm{SrZrO}_{3}: \mathrm{Gd}_{2} \mathrm{O}_{3}$ system, the calculated $\mathrm{m}$ is 1.94; therefore, the $\mathrm{m}$ is set to 2 for domain-matching. ${ }^{* *}$ Bulk lattice constant of $\mathrm{Gd}_{2} \mathrm{O}_{3}$ is $10.80 \AA$. The plane spacing for $\mathrm{Gd}_{2} \mathrm{O}_{3}(004)$ is $10.80 \AA / 4=2.7 \AA$.

Such vertical interface strain has been used to tune functional properties in oxides. Room-temperature ferroelectricity in vertically strained $\mathrm{SrTiO}_{3}$ nanocomposite with $\mathrm{MgO}$ nanopillars embedded in the strained $\mathrm{SrTiO}_{3}$ matrix has been demonstrated [46]. An out-of-plane strain of $\sim 1.5 \%$ was observed in the film matrix. Elastic coupling between $\mathrm{MgO}$ and $\mathrm{SrTiO}_{3}$ can be confirmed by etching away the $\mathrm{MgO}$ pillars, after which the lattice parameter of the $\mathrm{SrTiO}_{3}$ relaxes to $3.911 \AA$, as shown in Figure 12 [12]. The measured strain was corroborated by phase-field modeling to explore the spatial distribution of the strain and the resultant polarization. The $\mathrm{T}_{\mathrm{C}}$ was extracted from optical second-harmonic generation (SHG) measurements. The phase transition was found to be very broad, which was consistent with the non-uniform strain distribution and the non-uniformity shown in the piezoelectric force microscopy measurement.

A multiferroic epitaxial nanocomposite of $\mathrm{CoFe}_{2} \mathrm{O}_{4}$ nanopillars in a matrix of $\mathrm{BaTiO}_{3}$ was demonstrated [118]. The $\mathrm{CoFe}_{2} \mathrm{O}_{4}$ nanopillars experienced an out-of-plane compressive strain of $0.8 \%$. The coupling between the ferroelectric perovskite $\mathrm{BaTiO}_{3}$ and the ferrimagnetic spinel $\mathrm{CoFe}_{2} \mathrm{O}_{4}$ allowed the interconversion of energies stored in electric and magnetic fields to create an emergent ferroelectromagnet. The magnetoelectric coupling could be explained by the strong elastic interactions between the two phases by thermodynamic analyses, which was also further supported by the fact that the coupling could not be reproduced in multilayer structures due to the substrate clamping effect. 


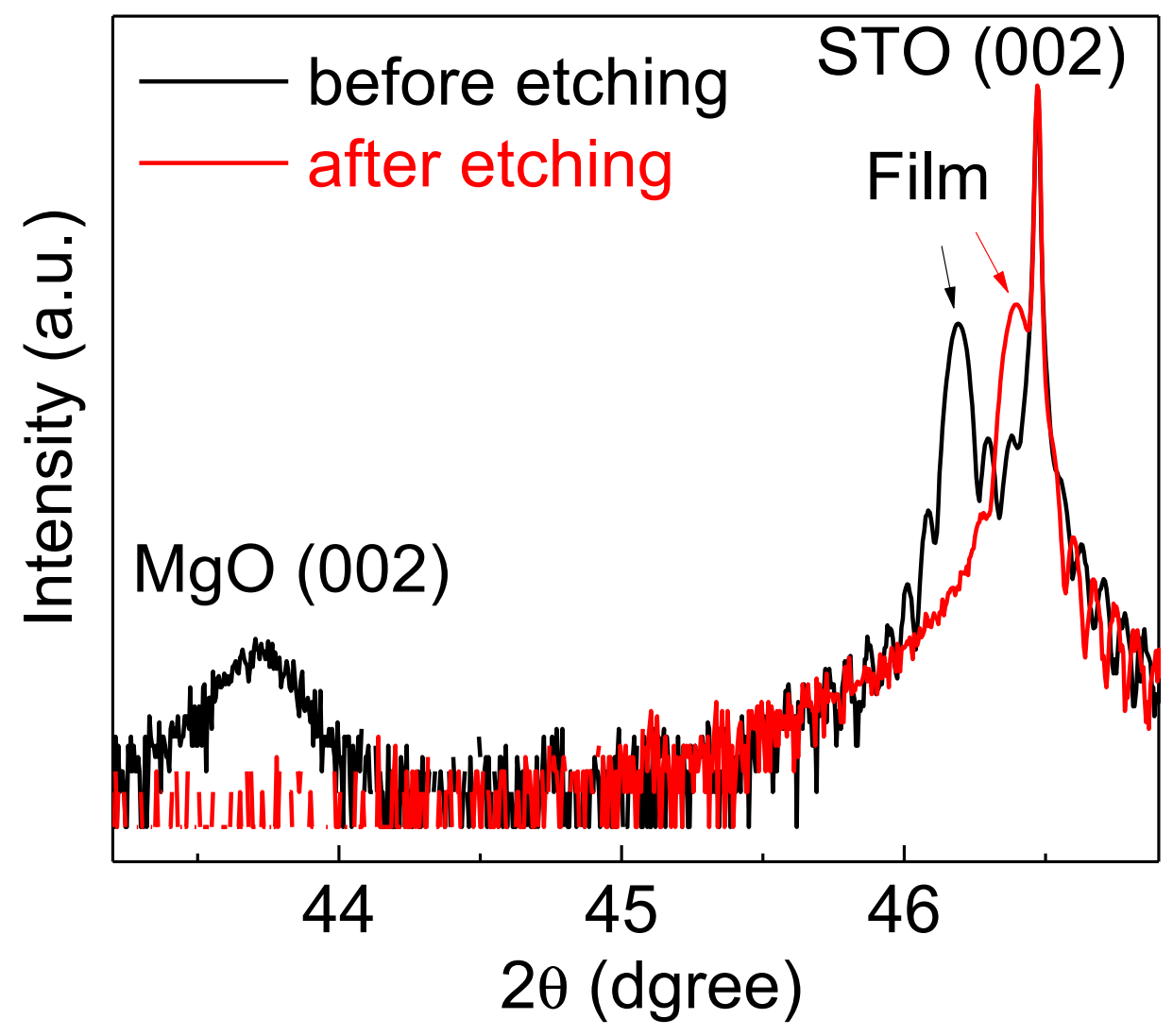

Figure 12. X-ray diffraction $\theta-2 \theta$ scans of $\mathrm{SrTiO}_{3}: \mathrm{MgO}$ vertically aligned nanocomposite films deposited on $\mathrm{SrTiO}_{3}$ substrate before and after etching off $\mathrm{MgO}$ nanopillars. Reprinted with permission from ref. [11]. Copyright 2019, Wiley.

Chen et al. explored the vertical strain engineering of the $\mathrm{La}_{0.7} \mathrm{Sr}_{0.3} \mathrm{MnO}_{3}$ system via incorporating nanopillars of $\mathrm{ZnO}$ and $\mathrm{MgO}$ in the nanocomposites [32]. The strain in the $\mathrm{La}_{0.7} \mathrm{Sr}_{0.3} \mathrm{MnO}_{3}: \mathrm{MgO}$ nanocomposites was much larger than that in the $\mathrm{La}_{0.7} \mathrm{Sr}_{0.3} \mathrm{MnO}_{3}: \mathrm{ZnO}$ with the same volume of the second phase due to the larger lattice mismatch and elastic modulus mismatch. Figure 13 shows the comparative studies of the nanocomposites with different second-phase materials and volume ratios. The rise in resistivity for the $\mathrm{La}_{0.7} \mathrm{Sr}_{0.3} \mathrm{MnO}_{3}: \mathrm{ZnO}$ at $\sim 50 \%$ of second-phase $(\mathrm{ZnO})$ volume can be explained by a secondphase-induced volume effect. On the other hand, the sharp drop of over 10 times in resistivity of $\mathrm{La}_{0.7} \mathrm{Sr}_{0.3} \mathrm{MnO}_{3}: \mathrm{MgO}$ happens at only $20 \%$ second-phase $(\mathrm{MgO})$ volume which is quite below the volume-induced percolation threshold. The experimental results, therefore, could predominantly be explained by the vertical strain effects. Vertical strain effects could also be the cause of the large drop in the metal-to-insulator transition temperature from $350 \mathrm{~K}$ of the bulk value of $\mathrm{La}_{0.7} \mathrm{Sr}_{0.3} \mathrm{MnO}_{3}$ to $150 \mathrm{~K}$ in the $\mathrm{La}_{0.7} \mathrm{Sr}_{0.3} \mathrm{MnO}_{3}: \mathrm{MgO}$ nanocomposite.

It is also noted that the strain on the LSMO matrix could be tuned via the density and size of the $\mathrm{MgO}$ nanopillars [32]. This, consequently, will affect the magnetic properties of the LSMO. For example, the LSMO:MgO nanocomposite with $5 \% \mathrm{MgO}$ inclusion showed an in-plane easy axis. With increasing the density of $\mathrm{MgO}$ nanopillars ( $15 \% \mathrm{MgO}$ inclusion), the easy axis switches to the out-of-plane direction. This switching of the magnetic anisotropy is correlated by the strain on the LSMO matrix exerted by the $\mathrm{MgO}$ nanopillars. 
(a)
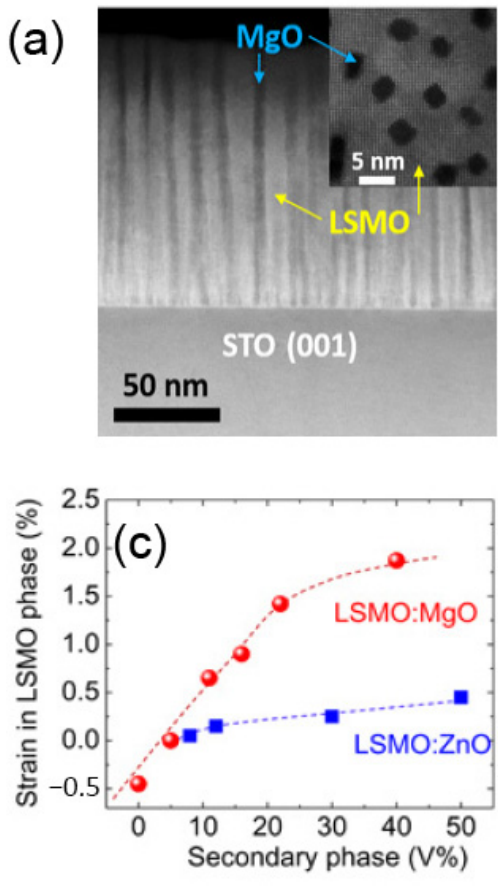

(b)
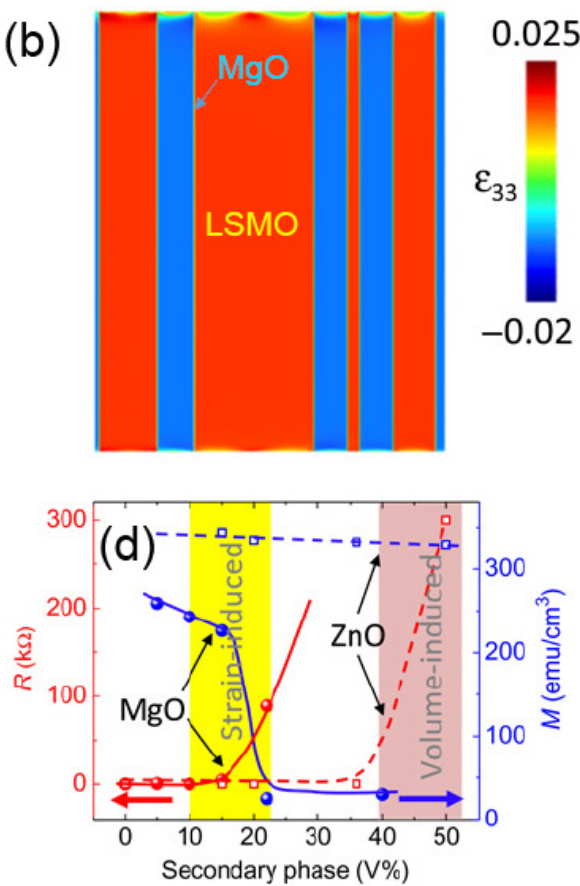

Figure 13. (a) A cross-sectional STEM image of an LSMO:MgO nanocomposite with phase-separated LSMO (white) and MgO (dark) phases. Inset: A top-view STEM image of the LSMO:MgO film with $\mathrm{MgO}$ nanopillars in the LSMO matrix. The $\mathrm{MgO}$ volume is $22 \%$. (b) The strain distribution in the LSMO matrix and $\mathrm{MgO}$ nanopillars ( $\mathrm{MgO}$ volume: $41 \%$ ) calculated by phase-field simulation. (c) The second-phase volume-dependent vertical strain in the LSMO matrix. The red (dot) data represent the LSMO:MgO system, and the blue (square) data set represent the LSMO:ZnO system. (d) The second-phase volume-dependent resistance at $100 \mathrm{~K}$ (red dataset) and saturated magnetization (blue dataset) at $20 \mathrm{~K}$ for the LSMO:MgO (solid curve) and LSMO:ZnO (dashed curves) nanocomposite films. Reprinted with permission from ref. [32]. Copyright 2016, AAAS.

\section{Future Prospects}

As discussed above, perovskite metal oxides have been considered as an extremely important class of materials for technological applications due to their versatile and tunable physical properties. At the same time, the unique interplay between the charge, spin, orbital and lattice degrees of freedom across similar energy scales also makes the physical properties of such materials very sensitive to both microstructural and compositional variations. This is understandable considering that the distortions of crystal structure resulting from the change in chemistry and/or the eight corner-shared $\left[\mathrm{BO}_{6}\right]$ octahedra will lead to the change in the electronic structure of the materials. Over the years, tremendous progress in controlled synthesis, advanced characterization at different length and time scales, and sophisticated modeling/simulation have helped us to fundamentally understand the processing-structure-property-performance relationship of perovskite metal oxides. Even so, more effort is much needed to further explore and design perovskites with desired properties, given their rich compositional diversity where the properties are closely tied to the crystal distortion such as the lattice strain. Below are some interesting and yet challenging research activities for the development of perovskite materials with enhanced, desired, and/or emergent properties.

(1) An in-depth and quantitative understanding of the role of interface and defect on the properties is critical for the rational design of novel perovskite materials. This is especially important where superlattice and/or vertically aligned nanocomposite are the building blocks [11]; 
(2) Substitution of ions via chemical pressure is one of the common approaches to strain the crystal structure. Much improved properteis could be achieved by forming multicomponent or high entropy perovskite oxides [119];

(3) Epitaxial strain resulting from the lattice mismatch between the substrate and the film has been widely investigated for a range of perovskite metal oxide films. The exploration of dynamic strain by laminating freestanding perovskite metal oxide films or membranes onto a stretchable substrate could provide possibilities for straintunable devices [8];

(4) Quantitative analysis of oxygen vacancies on the structural and physical properties of perovskite metal oxides is much needed. This is especially important for perovskites that are composed of cations with multiple valance states at the B site [120];

(5) The formation of nanocomposite represents an attractive strategy to achieve tunable properties. More effort is needed to address the challenges related to the controlled synthesis to achieve long-range ordered structures [97];

(6) While the most commonly studied perovskites are complex metal oxides, other perovskite materials, namely the halide perovskite [121], chalcogenide perovskite [122], and nitride perovskite [123], have attracted much attention lately. Halide perovskites, in particular, have attracted quite a lot of attention due to their potential applications for optoelectronic devices such as solar cells. However, the strain analysis and engineering in these thin films and devices have significantly different considerations than that of metal oxide perovskites, due to the soft ionic nature of the crystal lattice, generally non-epitaxial, and the complex interfaces of different charge transport layers [124-128]. While many studies has been undertaken and tremendous progress has been made in the synthesis and application of such materials, there are still many open questions related to the roles of strain, defect, interface, microstructure, and heterogeneity at different length scales on the physical properties of the materials. The recent review article published by Liu et al. summarizes the progress and challenges on this front admirably [129].

\section{Conclusions}

Perovskite metal oxides exhibit a multitude of important physical properties, such as metal-to-insulator transitions, superconductivity, ferroelectric, ferromagnetic, and magnetoresistive properties. As these properties are intimately linked with the structure of the perovskite, factors such as octahedral rotations, tilts and distortions, and chemical substitution with different sized cations can be also used to exert a chemical pressure to tailor these properties. Epitaxial strain is another lever that can be used to tune these properties in thin films by choosing an appropriate substrate with an appropriate lattice mismatch. Multilayers and/or superlattices take the advantage of layer thickness and multiple lateral interfaces to control the strain state of the assembly. Vertically aligned nanocomposites are an exciting way to construct strained thick films that is not possible in lateral heterostructures. Importantly, novel or improved functionalities, often not accessible from the individual constituents, could be produced through synergistic coupling interactions of known materials and lattice strain along the vertical directions. In the vertically aligned nanocomposite, it is possible to select one constituent as the active phase (typically perovskite metal oxide) with targeted functionality, and another as the passive phase (usually binary metal oxide), where the passive constituent is used to improve and/or tune the functionalities of the active phase. Such a strategy makes it possible to choose a much broader range of materials with targeted electrical, magnetic, optical, thermal, and/or mechanical properties for specific applications.

Author Contributions: Writing-original draft preparation, S.D. and Q.J.; writing-review and editing, S.D., A.C., W.N., B.P. and Q.J.; supervision, Q.J.; All authors have read and agreed to the published version of the manuscript. 
Funding: The work at the University at Buffalo was partially supported by the U.S. National Science Foundation under award number ECCS-1902623. The work at Los Alamos National Laboratory was supported by the NNSA's Laboratory Directed Research and Development Program. Los Alamos National Laboratory, an affirmative action equal opportunity employer, is managed by Triad National Security, LLC for the U.S. Department of Energy's NNSA, under contract 89233218CNA000001.

Institutional Review Board Statement: Not applicable.

Informed Consent Statement: Not applicable.

Data Availability Statement: No new data were created or analyzed in this study. Data sharing is not applicable to this article.

Acknowledgments: The work at Los Alamos National Laboratory was performed, in part, at the Center for Integrated Nanotechnologies (CINT), an Office of Science User Facility operated for the U.S. Department of Energy Office of Science. S.D. and Q.X.J. acknowledge the CINT Users Program.

Conflicts of Interest: The authors declare no conflict of interests.

\section{References}

1. Peña, M.A.; Fierro, J.L.G. Chemical structures and performance of perovskite oxides. Chem. Rev. 2001, 101, 1981-2018. [CrossRef] [PubMed]

2. Tilley, R.J.D. Perovskites: Structure-Property Relationships; John Wiley \& Sons: Hoboken, NJ, USA, 2016; ISBN 978-1-118-93566-8.

3. Coll, M.; Fontcuberta, J.; Althammer, M.; Bibes, M.; Boschker, H.; Calleja, A.; Cheng, G.; Cuoco, M.; Dittmann, R.; Dkhil, B.; et al. Towards oxide electronics: A roadmap. Appl. Surf. Sci. 2019, 482, 1-93. [CrossRef]

4. Liu, R.S.; Shen, C.H.; Hu, S.-F.; Chen, J.M. Chemical pressure control of curie temperature in $\mathrm{La}_{0.6}\left(\mathrm{Ba}_{0.4-\mathrm{X}} \mathrm{Ca}_{\mathrm{x}}\right) \mathrm{MnO}_{3}$. Mater. Chem. Phys. 2002, 75, 26-31. [CrossRef]

5. Mishra, D.K.; Sahu, D.R.; Mishra, P.K.; Behera, D.; Pradhan, A.K.; Roul, B.K. Chemical pressure effect on CMR behavior of Sr substituted $\mathrm{La}_{0 .}{ }_{67} \mathrm{Ca}_{0.33-\mathrm{X}} \mathrm{Sr}_{\mathrm{x}} \mathrm{MnO}_{3}$. Phys. B Condens. Matter 2007, 400,155-162. [CrossRef]

6. Mumtaz, F.; Nasir, S.; Jaffari, G.H.; Shah, S.I. Chemical pressure exerted by rare earth substitution in $\mathrm{BiFeO}_{3}$ : Effect on crystal symmetry, band structure and magnetism. J. Alloys Compd. 2021, 876, 160178. [CrossRef]

7. Tiittanen, T.; Karppinen, M. Structure evolution upon chemical and physical pressure in $\left(\mathrm{Sr}_{1-\mathrm{X}} \mathrm{Ba}_{\mathrm{x}}\right)_{2} \mathrm{FeSbO}_{6}$. J. Solid State Chem. 2017, 246, 245-251. [CrossRef]

8. Xu, R.; Huang, J.; Barnard, E.S.; Hong, S.S.; Singh, P.; Wong, E.K.; Jansen, T.; Harbola, V.; Xiao, J.; Wang, B.Y.; et al. Strain-induced room-temperature ferroelectricity in $\mathrm{SrTiO}_{3}$ membranes. Nat. Commun. 2020, 11, 3141. [CrossRef]

9. Schlom, D.G.; Chen, L.-Q.; Fennie, C.J.; Gopalan, V.; Muller, D.A.; Pan, X.; Ramesh, R.; Uecker, R. Elastic strain engineering of ferroic oxides. MRS Bull. 2014, 39, 118-130. [CrossRef]

10. Tsui, F.; Smoak, M.C.; Nath, T.K.; Eom, C.B. Strain-dependent magnetic phase diagram of epitaxial $\mathrm{La}_{0.67} \mathrm{Sr}_{0.33} \mathrm{MnO}_{3}$ thin films. Appl. Phys. Lett. 2000, 76, 2421-2423. [CrossRef]

11. Choi, K.J.; Biegalski, M.; Li, Y.L.; Sharan, A.; Schubert, J.; Uecker, R.; Reiche, P.; Chen, Y.B.; Pan, X.Q.; Gopalan, V.; et al. Enhancement of ferroelectricity in strained $\mathrm{BaTiO}_{3}$ thin films. Science 2004, 306, 1005-1009. [CrossRef] [PubMed]

12. Chen, A.; Su, Q.; Han, H.; Enriquez, E.; Jia, Q.X. Metal oxide nanocomposites: A perspective from strain, defect, and interface. Adv. Mater. 2019, 31, 1803241. [CrossRef] [PubMed]

13. Haeni, J.H.; Irvin, P.; Chang, W.; Uecker, R.; Reiche, P.; Li, Y.L.; Choudhury, S.; Tian, W.; Hawley, M.E.; Craigo, B.; et al. Room-temperature ferroelectricity in strained $\mathrm{SrTiO}_{3}$. Nature 2004, 430, 758-761. [CrossRef] [PubMed]

14. Pesquera, D.; Parsonnet, E.; Qualls, A.; Xu, R.; Gubser, A.J.; Kim, J.; Jiang, Y.; Velarde, G.; Huang, Y.; Hwang, H.Y.; et al. Beyond substrates: Strain engineering of ferroelectric membranes. Adv. Mater. 2020, 32, 2003780. [CrossRef] [PubMed]

15. Guo, H.; Dong, S.; Rack, P.D.; Budai, J.D.; Beekman, C.; Gai, Z.; Siemons, W.; Gonzalez, C.M.; Timilsina, R.; Wong, A.T.; et al. Strain doping: Reversible single-axis control of a complex oxide lattice via helium implantation. Phys. Rev. Lett. 2015, 114, 256801. [CrossRef] [PubMed]

16. Bhogra, A.; Masarrat, A.; Meena, R.; Hasina, D.; Bala, M.; Dong, C.-L.; Chen, C.-L.; Som, T.; Kumar, A.; Kandasami, A. Tuning the electrical and thermoelectric properties of $\mathrm{N}$ ion implanted $\mathrm{SrTiO}_{3}$ thin films and their conduction mechanisms. Sci. Rep. 2019, 9, 14486. [CrossRef]

17. Jena, A.K.; Kulkarni, A.; Miyasaka, T. Halide perovskite photovoltaics: Background, status, and future prospects. Chem. Rev. 2019, 119, 3036-3103. [CrossRef]

18. Dey, A.; Ye, J.; De, A.; Debroye, E.; Ha, S.K.; Bladt, E.; Kshirsagar, A.S.; Wang, Z.; Yin, J.; Wang, Y.; et al. State of the art and prospects for halide perovskite nanocrystals. ACS Nano 2021, 15, 10775-10981. [CrossRef]

19. Grabowska, E. Selected perovskite oxides: Characterization, preparation and photocatalytic properties-A review. Appl. Catal. B Environ. 2016, 186, 97-126. [CrossRef]

20. Bresolin, B.-M.; Park, Y.; Bahnemann, D.W. Recent progresses on metal halide perovskite-based material as potential photocatalyst. Catalysts 2020, 10, 709. [CrossRef] 
21. Hwang, J.; Rao, R.R.; Giordano, L.; Katayama, Y.; Yu, Y.; Shao-Horn, Y. Perovskites in catalysis and electrocatalysis. Science 2017, 358, 751-756. [CrossRef] [PubMed]

22. Wong, Y.-C.; Ng, J.D.A.; Tan, Z.-K. Perovskite-initiated photopolymerization for singly dispersed luminescent nanocomposites. Adv. Mater. 2018, 30, 1800774. [CrossRef] [PubMed]

23. Haque, M.A.; Kee, S.; Villalva, D.R.; Ong, W.-L.; Baran, D. Halide perovskites: Thermal transport and prospects for thermoelectricity. Adv. Sci. 2020, 7, 1903389. [CrossRef]

24. Wang, H.; Su, W.; Liu, J.; Wang, C. Recent development of N-type perovskite thermoelectrics. J. Mater. 2016, 2, 225-236. [CrossRef]

25. Panda, D.; Tseng, T.-Y. Perovskite oxides as resistive switching memories: A review. Ferroelectrics 2014, 471, 23-64. [CrossRef]

26. Rondinelli, J.M.; Spaldin, N.A. Structure and properties of functional oxide thin films: Insights from electronic-structure calculations. Adv. Mater. 2011, 23, 3363-3381. [CrossRef] [PubMed]

27. Klokholm, E.; Matthews, J.W.; Mayadas, A.F.; Angilello, J. Epitaxial strains and fracture in garnet films. AIP Conf. Proc. 1972, 5 , 105-109. [CrossRef]

28. Freund, L.B.; Suresh, S. Thin Film Materials: Stress, Defect Formation and Surface Evolution; Cambridge University Press: Cambridge, UK, 2004; ISBN 978-1-139-44982-3

29. Chaluvadi, S.K.; Ajejas, F.; Orgiani, P.; Lebargy, S.; Minj, A.; Flament, S.; Camarero, J.; Perna, P.; Méchin, L. Epitaxial strain and thickness dependent structural, electrical and magnetic properties of $\mathrm{La}_{0.67} \mathrm{Sr}_{0.33} \mathrm{MnO}_{3}$ films. J. Phys. Appl. Phys. 2020, $53,375005$. [CrossRef]

30. Adamo, C.; Ke, X.; Wang, H.Q.; Xin, H.L.; Heeg, T.; Hawley, M.E.; Zander, W.; Schubert, J.; Schiffer, P.; Muller, D.A. Effect of biaxial strain on the electrical and magnetic properties of (001) $\mathrm{La}_{0.7} \mathrm{Sr}_{0.3} \mathrm{MnO}_{3}$ thin films. Appl. Phys. Lett. 2009, 95, 112504. [CrossRef]

31. Yin, L.; Wang, C.; Shen, Q.; Zhang, L. Strain-induced curie temperature variation in $\mathrm{La}_{0.9} \mathrm{Sr}_{0.1} \mathrm{MnO}_{3}$ thin films. RSC Adv. 2016, 6, 96093-96102. [CrossRef]

32. Chen, A.; Hu, J.-M.; Lu, P.; Yang, T.; Zhang, W.; Li, L.; Ahmed, T.; Enriquez, E.; Weigand, M.; Su, Q.; et al. Role of scaffold network in controlling strain and functionalities of nanocomposite films. Sci. Adv. 2016, 2, e1600245. [CrossRef]

33. Berndt, L.M.; Balbarin, V.; Suzuki, Y. Magnetic anisotropy and strain states of (001) and (110) colossal magnetoresistance thin films. Appl. Phys. Lett. 2000, 77, 2903-2905. [CrossRef]

34. Hrouda, F. Theoretical models of magnetic anisotropy to strain relationship revisited. Phys. Earth Planet. Inter. 1993, 77, 237-249. [CrossRef]

35. Suzuki, Y.; Hwang, H.Y.; Cheong, S.-W.; van Dover, R.B. The role of strain in magnetic anisotropy of manganite thin films. Appl. Phys. Lett. 1997, 71, 140-142. [CrossRef]

36. Nath, T.K.; Rao, R.A.; Lavric, D.; Eom, C.B.; Wu, L.; Tsui, F. Effect of three-dimensional strain states on magnetic anisotropy of $\mathrm{La}_{0.8} \mathrm{Ca}_{0.2} \mathrm{MnO}_{3}$ epitaxial thin films. Appl. Phys. Lett. 1999, 74, 1615-1617. [CrossRef]

37. Huang, W.; Zhu, J.; Zeng, H.Z.; Wei, X.H.; Zhang, Y.; Li, Y.R. Strain induced magnetic anisotropy in highly epitaxial CoFe ${ }_{2} \mathrm{O}_{4}$ thin films. Appl. Phys. Lett. 2006, 89, 262506. [CrossRef]

38. Vailionis, A.; Boschker, H.; Siemons, W.; Houwman, E.P.; Blank, D.H.A.; Rijnders, G.; Koster, G. Misfit strain accommodation in epitaxial $\mathrm{ABO}_{3}$ perovskites: Lattice rotations and lattice modulations. Phys. Rev. B 2011, 83, 064101. [CrossRef]

39. Wang, H.S.; Wertz, E.; Hu, Y.F.; Li, Q.; Schlom, D.G. Role of strain in magnetotransport properties of $\operatorname{Pr}_{0.67} \mathrm{Sr}_{0.33} \mathrm{MnO}_{3}$ thin films. J. Appl. Phys. 2000, 87, 7409-7414. [CrossRef]

40. Boikov, Y.A.; Gunnarsson, R.; Claeson, T. Strain-enhanced phase separation affecting electro-and magnetotransport in $\mathrm{La}_{0.67} \mathrm{Ca}_{0.33} \mathrm{MnO}_{3}$ films. J. Appl. Phys. 2004, 96, 435-442. [CrossRef]

41. Yang, F.; Kemik, N.; Biegalski, M.D.; Christen, H.M.; Arenholz, E.; Takamura, Y. Strain engineering to control the magnetic and magnetotransport properties of $\mathrm{La}_{0.67} \mathrm{Sr}_{0.33} \mathrm{MnO}_{3}$ thin films. Appl. Phys. Lett. 2010, 97, 092503. [CrossRef]

42. Streiffer, S.K.; Eastman, J.A.; Fong, D.D.; Thompson, C.; Munkholm, A.; Murty, M.R.; Auciello, O.; Bai, G.R.; Stephenson, G.B Observation of nanoscale $180^{\circ}$ stripe domains in ferroelectric $\mathrm{PbTiO}_{3}$ thin films. Phys. Rev. Lett. 2002, 89, 067601. [CrossRef]

43. Yanase, N.Y.N.; Abe, K.A.K.; Fukushima, N.F.N.; Kawakubo, T.K.T. Thickness dependence of ferroelectricity in heteroepitaxial $\mathrm{BaTiO}_{3}$ thin film capacitors. Jpn. J. Appl. Phys. 1999, 38, 5305. [CrossRef]

44. Abe, K.; Yanase, N.; Sano, K.; Izuha, M.; Fukushima, N.; Kawakubo, T. Modification of ferroelectricity in heteroepitaxial (Ba,Sr) $\mathrm{TiO}_{3}$ films for non-volatile memory applications. Integr. Ferroelectr. 1998, 21, 197-206. [CrossRef]

45. Christen, H.M.; Specht, E.D.; Silliman, S.S.; Harshavardhan, K.S. Ferroelectric and antiferroelectric coupling in superlattices of paraelectric perovskites at room temperature. Phys. Rev. B 2003, 68, 020101. [CrossRef]

46. Enriquez, E.; Li, Q.; Bowlan, P.; Lu, P.; Zhang, B.; Li, L.; Wang, H.; Taylor, A.J.; Yarotski, D.; Prasankumar, R.P.; et al. Induced ferroelectric phases in $\mathrm{SrTiO}_{3}$ by a nanocomposite approach. Nanoscale 2020, 12, 18193-18199. [CrossRef] [PubMed]

47. Sangle, A.L.; Lee, O.J.; Kursumovic, A.; Zhang, W.; Chen, A.; Wang, H.; MacManus-Driscoll, J.L. Very high commutation quality factor and dielectric tunability in nanocomposite $\mathrm{SrTiO}_{3}$ thin films with $\mathrm{T}_{\mathrm{c}}$ enhanced to $>300{ }^{\circ} \mathrm{C}$. Nanoscale 2018, 10, 3460-3468. [CrossRef] [PubMed]

48. Attfield, J.P. A simple approach to lattice effects in conducting perovskite-type oxides. Chem. Mater. 1998, 10, 3239-3248. [CrossRef]

49. Dawson, J.A.; Sinclair, D.C.; Harding, J.H.; Freeman, C.L. A-site strain and displacement in $\mathrm{Ba}_{1-x} \mathrm{Ca}_{x} \mathrm{TiO}_{3}$ and $\mathrm{Ba}_{1-x} \mathrm{Sr}_{x} \mathrm{TiO}_{3}$ and the consequences for the curie temperature. Chem. Mater. 2014, 26, 6104-6112. [CrossRef] 
50. Azad, A.K.; Eriksson, S.-G.; Ivanov, S.A.; Mathieu, R.; Svedlindh, P. Influence of a-site cations on structural and magnetic properties in the double perovskites $\mathrm{Ca}_{2-\mathrm{x}} \mathrm{Sr}_{\mathrm{x}} \mathrm{MnWO}_{6}$ and $\mathrm{Sr}_{2-\mathrm{x}} \mathrm{Ba}_{\mathrm{x}} \mathrm{MnWO}_{6}(0 \leq \mathrm{x} \leq 2.0)$. Ferroelectrics 2004, 302, 181-185. [CrossRef]

51. Rondinelli, J.M.; May, S.J.; Freeland, J.W. Control of octahedral connectivity in perovskite oxide heterostructures: An emerging route to multifunctional materials discovery. MRS Bull. 2012, 37, 261-270. [CrossRef]

52. Urushibara, A.; Moritomo, Y.; Arima, T.; Asamitsu, A.; Kido, G.; Tokura, Y. Insulator-metal transition and giant magnetoresistance in $\mathrm{La}_{1-\mathrm{x}} \mathrm{Sr}_{\mathrm{x}} \mathrm{MnO}_{3}$. Phys. Rev. B 1995, 51, 14103-14109. [CrossRef] [PubMed]

53. Uehara, M.; Mori, S.; Chen, C.H.; Cheong, S.-W. Percolative phase separation underlies colossal magnetoresistance in mixed-valent manganites. Nature 1999, 399, 560-563. [CrossRef]

54. Raveau, B.; Maignan, A.; Martin, C.; Hervieu, M. Colossal magnetoresistance manganite perovskites: Relations between crystal chemistry and properties. Chem. Mater. 1998, 10, 2641-2652. [CrossRef]

55. Rao, C.N.R.; Arulraj, A.; Cheetham, A.K.; Raveau, B. Charge ordering in the rare earth manganates: The experimental situation. J. Phys. Condens. Matter 2000, 12, R83-R106. [CrossRef]

56. Raveau, B. Impact of crystal chemistry upon the physics of strongly correlated electrons in oxides. Angew. Chem. Int. Ed. 2013, 52, 167-175. [CrossRef] [PubMed]

57. Sinclair, D.C.; Attfield, J.P. The influence of A-cation disorder on the Curie temperature of ferroelectric $\mathrm{ATiO}_{3}$ perovskites. Chem. Commun. 1999, 16, 1497-1498. [CrossRef]

58. Hubert, C.; Levy, J.; Carter, A.C.; Chang, W.; Kiechoefer, S.W.; Horwitz, J.S.; Chrisey, D.B. Confocal scanning optical microscopy of $\mathrm{Ba}_{x} \mathrm{Sr}_{1-\mathrm{x}} \mathrm{TiO}_{3}$ thin films. Appl. Phys. Lett. 1997, 71, 3353-3355. [CrossRef]

59. Gim, Y.; Hudson, T.; Fan, Y.; Kwon, C.; Findikoglu, A.T.; Gibbons, B.J.; Park, B.H.; Jia, Q.X. Microstructure and dielectric properties of $\mathrm{Ba}_{1-\mathrm{x}} \mathrm{Sr}_{\mathrm{x}} \mathrm{TiO}_{3}$ films grown on $\mathrm{LaAlO}_{3}$ substrates. Appl. Phys. Lett. 2000, 77, 1200-1202. [CrossRef]

60. Park, B.H.; Li, Y.R.; Xiong, J.; Jia, Q.X. Dielectric properties of epitaxial $\mathrm{Ba}_{1-\mathrm{X}} \mathrm{Sr}_{\mathrm{x}} \mathrm{TiO}_{3}$ films on MgO substrates. Funct. Mater. Lett. 2011, 4, 41-44. [CrossRef]

61. Islam, M.A.; Rondinelli, J.M.; Spanier, J.E. Normal mode determination of perovskite crystal structures with octahedral rotations: Theory and applications. J. Phys. Condens. Matter 2013, 25, 175902. [CrossRef] [PubMed]

62. People, R.; Bean, J.C. Calculation of critical layer thickness versus lattice mismatch for $\mathrm{Ge}_{\mathrm{x}} \mathrm{Si}_{1-\mathrm{x}} / \mathrm{Si}$ strained-layer heterostructures. Appl. Phys. Lett. 1985, 47, 322-324. [CrossRef]

63. Chen, Y.B.; Sun, H.P.; Katz, M.B.; Pan, X.Q.; Choi, K.J.; Jang, H.W.; Eom, C.B. Interface structure and strain relaxation in BaTiO 3 thin films grown on $\mathrm{GdScO}_{3}$ and $\mathrm{DyScO}_{3}$ substrates with buried coherent $\mathrm{SrRuO}_{3}$ layer. Appl. Phys. Lett. 2007, $91,252906$. [CrossRef]

64. Dimakis, E.; Iliopoulos, E.; Tsagaraki, K.; Adikimenakis, A.; Georgakilas, A. Biaxial strain and lattice constants of InN (0001) films grown by plasma-assisted molecular beam epitaxy. Appl. Phys. Lett. 2006, 88, 191918. [CrossRef]

65. Janolin, P.E.; Anokhin, A.S.; Gui, Z.; Mukhortov, V.M.; Golovko, Y.I.; Guiblin, N.; Ravy, S.; El Marssi, M.; Yuzyuk, Y.I.; Bellaiche, L. Strain engineering of perovskite thin films using a single substrate. J. Phys. Condens. Matter 2014, 26, 292201. [CrossRef] [PubMed]

66. Zhang, L.; Yuan, Y.; Lapano, J.; Brahlek, M.; Lei, S.; Kabius, B.; Gopalan, V.; Engel-Herbert, R. Continuously tuning epitaxial strains by thermal mismatch. ACS Nano 2018, 12, 1306-1312. [CrossRef] [PubMed]

67. Rasic, D.; Sachan, R.; Prater, J.; Narayan, J. Structure-property correlations in thermally processed epitaxial LSMO films. Acta Mater. 2019, 163, 189-198. [CrossRef]

68. Vailionis, A. The Effects of Strain on Crystal Structure and Properties during Epitaxial Growth of Oxides. In Epitaxial Growth of Complex Metal Oxides; Elsevier: Amsterdam, The Netherlands, 2015; pp. 175-207, ISBN 978-1-78242-245-7.

69. Guzman, R.; Gazquez, J.; Rouco, V.; Palau, A.; Magen, C.; Varela, M.; Arbiol, J.; Obradors, X.; Puig, T. Strain-driven broken twin boundary coherence in $\mathrm{YBa}_{2} \mathrm{Cu}_{3} \mathrm{O}_{7-\delta}$ nanocomposite thin films. Appl. Phys. Lett. 2013, 102, 081906. [CrossRef]

70. Arpaia, R.; Golubev, D.; Baghdadi, R.; Ciancio, R.; Dražić, G.; Orgiani, P.; Montemurro, D.; Bauch, T.; Lombardi, F. Transport properties of ultrathin $\mathrm{YBa}_{2} \mathrm{Cu}_{3} \mathrm{O}_{7}$ nanowires: A route to single-photon detection. Phys. Rev. B 2017, 96, 064525. [CrossRef]

71. Jia, C.-L.; Mi, S.-B.; Jin, L. Quantitative HRTEM and its application in the study of oxide materials. Chin. Phys. B 2018, 27, 056803. [CrossRef]

72. Liao, Z.; Huijben, M.; Zhong, Z.; Gauquelin, N.; Macke, S.; Green, R.J.; van Aert, S.; Verbeeck, J.; van Tendeloo, G.; Held, K.; et al. Controlled lateral anisotropy in correlated manganite heterostructures by interface-engineered oxygen octahedral coupling. Nat. Mater. 2016, 15, 425-431. [CrossRef] [PubMed]

73. Kan, D.; Aso, R.; Sato, R.; Haruta, M.; Kurata, H.; Shimakawa, Y. Tuning magnetic anisotropy by interfacially engineering the oxygen coordination environment in a transition metal oxide. Nat. Mater. 2016, 15, 432-437. [CrossRef] [PubMed]

74. Fang, Y.; Wei, H.; Dong, Q.; Huang, J. Quantification of re-absorption and re-emission processes to determine photon recycling efficiency in perovskite single crystals. Nat. Commun. 2017, 8, 1-9. [CrossRef] [PubMed]

75. He, L.; Vanderbilt, D. First-principles study of oxygen-vacancy pinning of domain walls in PbTiO 3 . Phys. Rev. B 2003, 68, 134103. [CrossRef]

76. Eichel, R.-A. Structural and dynamic properties of oxygen vacancies in perovskite oxides-Analysis of defect chemistry by modern multi-frequency and pulsed EPR techniques. Phys. Chem. Chem. Phys. 2010, 13, 368-384. [CrossRef] [PubMed]

77. Herklotz, A.; Lee, D.; Guo, E.-J.; Meyer, T.L.; Petrie, J.R.; Lee, H.N. Strain coupling of oxygen non-stoichiometry in perovskite thin films. J. Phys. Condens. Matter 2017, 29, 493001. [CrossRef] [PubMed] 
78. Yang, Q.; Cao, J.X.; Zhou, Y.C.; Zhang, Y.; Ma, Y.; Lou, X.J. Tunable oxygen vacancy configuration by strain engineering in perovskite ferroelectrics from first-principles study. Appl. Phys. Lett. 2013, 103, 142911. [CrossRef]

79. Al-Hamadany, R.; Goss, J.P.; Briddon, P.R.; Mojarad, S.A.; Al-Hadidi, M.; O'Neill, A.G.; Rayson, M.J. Oxygen vacancy migration in compressively strained $\mathrm{SrTiO}_{3}$. J. Appl. Phys. 2013, 113, 024108. [CrossRef]

80. Ma, J.; Zhang, Y.; Wu, L.; Song, C.; Zhang, Q.; Zhang, J.; Nan, C.-W.; Ma, J. Strain-induced modulation of oxygen vacancies and magnetic properties in $\mathrm{La}_{0.5} \mathrm{Sr}_{0.5} \mathrm{MnO}_{3}$ thin films. MRS Commun. 2016, 6, 354-359. [CrossRef]

81. Rajak, P.; Knez, D.; Chaluvadi, S.K.; Orgiani, P.; Rossi, G.; Méchin, L.; Ciancio, R. Evidence of Mn-ion structural displacements correlated with oxygen vacancies in $\mathrm{La}_{0.7} \mathrm{Sr}_{0.3} \mathrm{MnO}_{3}$ interfacial dead layers. ACS Appl. Mater. Interfaces 2021, 13, 55666-55675. [CrossRef] [PubMed]

82. Li, Y.L.; Choudhury, S.; Haeni, J.H.; Biegalski, M.D.; Vasudevarao, A.; Sharan, A.; Ma, H.Z.; Levy, J.; Gopalan, V.; Trolier-McKinstry, S.; et al. Phase transitions and domain structures in strained pseudocubic (100) $\mathrm{SrTiO}_{3}$ thin films. Phys. Rev. B 2006, 73, 184112. [CrossRef]

83. Vasudevarao, A.; Kumar, A.; Tian, L.; Haeni, J.H.; Li, Y.L.; Eklund, C.-J.; Jia, Q.X.; Uecker, R.; Reiche, P.; Rabe, K.M.; et al. Multiferroic domain dynamics in strained strontium titanate. Phys. Rev. Lett. 2006, 97, 257602. [CrossRef] [PubMed]

84. Pertsev, N.A.; Tagantsev, A.K.; Setter, N. Phase transitions and strain-induced ferroelectricity in $\mathrm{SrTiO}_{3}$ epitaxial thin films. Phys. Rev. B 2000, 61, R825-R829. [CrossRef]

85. Grünebohm, A.; Marathe, M.; Ederer, C. Ab initio phase diagram of $\mathrm{BaTiO}_{3}$ under epitaxial strain revisited. Appl. Phys. Lett. 2015, 107, 102901. [CrossRef]

86. Pertsev, N.A.; Koukhar, V.G.; Waser, R.; Hoffmann, S. Effects of domain formation on the dielectric properties of ferroelectric thin films. Integr. Ferroelectr. 2001, 32, 235-249. [CrossRef]

87. Li, Y.L.; Chen, L.Q. Temperature-strain phase diagram for $\mathrm{BaTiO}_{3}$ thin films. Appl. Phys. Lett. 2006, 88, 072905. [CrossRef]

88. Pertsev, N.A.; Koukhar, V.G. Polarization instability in polydomain ferroelectric epitaxial thin films and the formation of heterophase structures. Phys. Rev. Lett. 2000, 84, 3722-3725. [CrossRef] [PubMed]

89. Koukhar, V.G.; Pertsev, N.A.; Waser, R. Thermodynamic theory of epitaxial ferroelectric thin films with dense domain structures. Phys. Rev. B 2001, 64, 214103. [CrossRef]

90. Fong, D.D.; Stephenson, G.B.; Streiffer, S.K.; Eastman, J.A.; Auciello, O.; Fuoss, P.H.; Thompson, C. Ferroelectricity in ultrathin perovskite films. Science 2004, 304, 1650-1653. [CrossRef] [PubMed]

91. Junquera, J.; Ghosez, P. Critical thickness for ferroelectricity in perovskite ultrathin films. Nature 2003, 422, 506-509. [CrossRef] [PubMed]

92. Pertsev, N.A.; Zembilgotov, A.G.; Tagantsev, A.K. Effect of mechanical boundary conditions on phase diagrams of epitaxial ferroelectric thin films. Phys. Rev. Lett. 1998, 80, 1988-1991. [CrossRef]

93. Sheng, G.; Zhang, J.X.; Li, Y.L.; Choudhury, S.; Jia, Q.X.; Liu, Z.K.; Chen, L.Q. Domain stability of $\mathrm{PbTiO}_{3}$ thin films under anisotropic misfit strains: Phase-field simulations. J. Appl. Phys. 2008, 104, 054105. [CrossRef]

94. Lee, H.N.; Christen, H.M.; Chisholm, M.F.; Rouleau, C.M.; Lowndes, D.H. Strong polarization enhancement in asymmetric three-component ferroelectric superlattices. Nature 2005, 433, 395-399. [CrossRef] [PubMed]

95. Ogawa, Y.; Yamada, H.; Ogasawara, T.; Arima, T.; Okamoto, H.; Kawasaki, M.; Tokura, Y. Nonlinear magneto-optical Kerr rotation of an oxide superlattice with artificially broken symmetry. Phys. Rev. Lett. 2003, 90, 217403. [CrossRef] [PubMed]

96. Park, B.H.; Peterson, E.J.; Jia, Q.X.; Lee, J.; Zeng, X.; Si, W.; Xi, X.X. Effects of very thin strain layers on dielectric properties of epitaxial $\mathrm{Ba}_{0.6} \mathrm{Sr}_{0.4} \mathrm{TiO}_{3}$ films. Appl. Phys. Lett. 2001, 78, 533-535. [CrossRef]

97. Tenne, D.A.; Bruchhausen, A.; Lanzillotti-Kimura, N.D.; Fainstein, A.; Katiyar, R.S.; Cantarero, A.; Soukiassian, A.; Vaithyanathan, V.; Haeni, J.H.; Tian, W.; et al. Probing nanoscale ferroelectricity by ultraviolet Raman spectroscopy. Science 2006, 313, 1614-1616. [CrossRef] [PubMed]

98. Lee, J.H.; Fang, L.; Vlahos, E.; Ke, X.; Jung, Y.W.; Kourkoutis, L.F.; Kim, J.-W.; Ryan, P.J.; Heeg, T.; Roeckerath, M.; et al. A strong ferroelectric ferromagnet created by means of spin-lattice coupling. Nature 2010, 466, 954-958. [CrossRef]

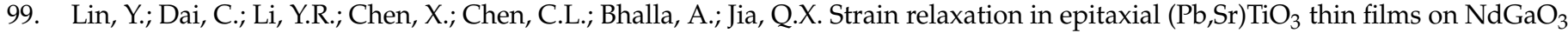
substrates. Appl. Phys. Lett. 2010, 96, 102901. [CrossRef]

100. Harrington, S.A.; Zhai, J.; Denev, S.; Gopalan, V.; Wang, H.; Bi, Z.; Redfern, S.A.T.; Baek, S.-H.; Bark, C.W.; Eom, C.-B.; et al Thick lead-free ferroelectric films with high curie temperatures through nanocomposite-induced strain. Nat. Nanotechnol. 2011, 6, 491-495. [CrossRef] [PubMed]

101. Sun, S.; Yang, K.-Y.; Wang, C.-M.; Juan, T.-K.; Chen, W.T.; Liao, C.Y.; He, Q.; Xiao, S.; Kung, W.-T.; Guo, G.-Y.; et al. High-efficiency broadband anomalous reflection by gradient meta-surfaces. Nano Lett. 2012, 12, 6223-6229. [CrossRef] [PubMed]

102. Chen, A.; Jia, Q.X. A pathway to desired functionalities in vertically aligned nanocomposites and related architectures. MRS Bull. 2021, 46, 115-122. [CrossRef]

103. Ni, Y.; Khachaturyan, A.G. From chessboard tweed to chessboard nanowire structure during pseudospinodal decomposition. Nat. Mater. 2009, 8, 410-414. [CrossRef] [PubMed]

104. Ni, Y.; Rao, W.; Khachaturyan, A.G. Pseudospinodal mode of decomposition in films and formation of chessboard-like nanostructure. Nano Lett. 2009, 9, 3275-3281. [CrossRef] [PubMed] 
105. Moshnyaga, V.; Damaschke, B.; Shapoval, O.; Belenchuk, A.; Faupel, J.; Lebedev, O.I.; Verbeeck, J.; van Tendeloo, G.; Mücksch, M.; Tsurkan, V.; et al. Structural phase transition at the percolation threshold in epitaxial $\left(\mathrm{La}_{0.7} \mathrm{Ca}_{0.3} \mathrm{MnO}_{3}\right)_{1-\mathrm{x}}:(\mathrm{MgO})_{\mathrm{x}}$ nanocomposite films. Nat. Mater. 2003, 2, 247-252. [CrossRef] [PubMed]

106. Zhang, W.; Fan, M.; Li, L.; Chen, A.; Su, Q.; Jia, Q.X.; MacManus-Driscoll, J.L.; Wang, H. Heterointerface design and strain tuning in epitaxial $\mathrm{BiFeO}_{3}: \mathrm{CoFe}_{2} \mathrm{O}_{4}$ nanocomposite films. Appl. Phys. Lett. 2015, 107, 212901. [CrossRef]

107. Zheng, H.; Kreisel, J.; Chu, Y.-H.; Ramesh, R.; Salamanca-Riba, L. Heteroepitaxially enhanced magnetic anisotropy in BaTiO ${ }_{3}-$ $\mathrm{CoFe}_{2} \mathrm{O}_{4}$ nanostructures. Appl. Phys. Lett. 2007, 90, 113113. [CrossRef]

108. Zhang, W.; Chen, A.; Jian, J.; Zhu, Y.; Chen, L.; Lu, P.; Jia, Q.X.; MacManus-Driscoll, J.L.; Zhang, X.; Wang, H. Strong perpendicular exchange bias in epitaxial $\mathrm{La}_{0.7} \mathrm{Sr}_{0.3} \mathrm{MnO}_{3}: \mathrm{BiFeO}_{3}$ nanocomposite films through vertical interfacial coupling. Nanoscale 2015, 7, 13808-13815. [CrossRef]

109. Zhao, R.; Li, W.; Lee, J.H.; Choi, E.M.; Liang, Y.; Zhang, W.; Tang, R.; Wang, H.; Jia, Q.X.; MacManus-Driscoll, J.L.; et al. Precise tuning of $\left(\mathrm{YBa}_{2} \mathrm{Cu}_{3} \mathrm{O}_{7-\delta}\right)_{1-\mathrm{x}}:\left(\mathrm{BaZrO}_{3}\right)_{\mathrm{x}}$ thin film nanocomposite structures. Adv. Funct. Mater. 2014, 24, 5240-5245. [CrossRef]

110. MacManus-Driscoll, J.L.; Zerrer, P.; Wang, H.; Yang, H.; Yoon, J.; Fouchet, A.; Yu, R.; Blamire, M.G.; Jia, Q.X. Strain control and spontaneous phase ordering in vertical nanocomposite heteroepitaxial thin films. Nat. Mater. 2008, 7, 314-320. [CrossRef] [PubMed]

111. Chen, A.; Zhang, W.; Khatkhatay, F.; Su, Q.; Tsai, C.-F.; Chen, L.; Jia, Q.X.; MacManus-Driscoll, J.L.; Wang, H. Magnetotransport properties of quasi-one-dimensionally channeled vertically aligned heteroepitaxial nanomazes. Appl. Phys. Lett. 2013, 102, 093114. [CrossRef]

112. Chen, A.; Zhang, W.; Jian, J.; Wang, H.; Tsai, C.-F.; Su, Q.; Jia, Q.X.; MacManus-Driscoll, J.L. Role of boundaries on low-field magnetotransport properties of $\mathrm{La}_{0.7} \mathrm{Sr}_{0.3} \mathrm{MnO}_{3}$-Based nanocomposite thin films. J. Mater. Res. 2013, 28, 1707-1715. [CrossRef]

113. MacManus-Driscoll, J.L.; Suwardi, A.; Wang, H. Composite epitaxial thin films: A new platform for tuning, probing, and exploiting mesoscale oxides. MRS Bull. 2015, 40, 933-942. [CrossRef]

114. Chen, A.; Bi, Z.; Hazariwala, H.; Zhang, X.; Su, Q.; Chen, L.; Jia, Q.X.; MacManus-Driscoll, J.L.; Wang, H. Microstructure, magnetic, and low-field magnetotransport properties of self-assembled $\left(\mathrm{La}_{0.7} \mathrm{~S}_{\mathrm{r} 0.3} \mathrm{MnO}_{3}\right)_{0.5}:\left(\mathrm{CeO}_{2}\right)_{0.5}$ vertically aligned nanocomposite thin films. Nanotechnology 2011, 22, 315712. [CrossRef]

115. Lee, S.; Zhang, W.; Khatkhatay, F.; Jia, Q.X.; Wang, H.; MacManus-Driscoll, J.L. Strain tuning and strong enhancement of ionic conductivity in $\mathrm{SrZrO}_{3}-\mathrm{RE}_{2} \mathrm{O}_{3}(\mathrm{RE}=\mathrm{Sm}, \mathrm{Eu}, \mathrm{Gd}, \mathrm{Dy}$, and $\mathrm{Er})$ nanocomposite films. Adv. Funct. Mater. 2015, 25, 4328-4333. [CrossRef]

116. Li, W.; Zhang, W.; Wang, L.; Gu, J.; Chen, A.; Zhao, R.; Liang, Y.; Guo, H.; Tang, R.; Wang, C.; et al. Vertical interface induced dielectric relaxation in nanocomposite $\left(\mathrm{BaTiO}_{3}\right)_{1-\mathrm{x}}:\left(\mathrm{Sm}_{2} \mathrm{O}_{3}\right)_{\mathrm{x}}$ thin films. Sci. Rep. 2015, 5, 11335. [CrossRef] [PubMed]

117. Lee, S.; Sangle, A.; Lu, P.; Chen, A.; Zhang, W.; Lee, J.S.; Wang, H.; Jia, Q.X.; MacManus-Driscoll, J.L. Novel electroforming-free nanoscaffold memristor with very high uniformity, tunability, and density. Adv. Mater. 2014, 26, 6284-6289. [CrossRef] [PubMed]

118. Zheng, H.; Wang, J.; Lofland, S.E.; Ma, Z.; Mohaddes-Ardabili, L.; Zhao, T.; Salamanca-Riba, L.; Shinde, S.R.; Ogale, S.B.; Bai, F.; et al. Multiferroic $\mathrm{BaTiO}_{3}-\mathrm{CoFe}_{2} \mathrm{O}_{4}$ nanostructures. Science 2004, 303, 661-663. [CrossRef] [PubMed]

119. Oses, C.; Toher, C.; Curtarolo, S. High-entropy ceramics. Nat. Rev. Mater. 2020, 5, 295-309. [CrossRef]

120. Enriquez, E.; Chen, A.; Harrell, Z.; Dowden, P.; Koskelo, N.; Roback, J.; Janoschek, M.; Chen, C.; Jia, Q.X. Oxygen vacancy-tuned physical properties in perovskite thin films with multiple B-site valance states. Sci. Rep. 2017, 7, 46184. [CrossRef] [PubMed]

121. Burschka, J.; Pellet, N.; Moon, S.-J.; Humphry-Baker, R.; Gao, P.; Nazeeruddin, M.K.; Grätzel, M. Sequential deposition as a route to high-performance perovskite-sensitized solar cells. Nature 2013, 499, 316-319. [CrossRef]

122. Wang, Y.; Sato, N.; Fujino, T. Synthesis of BaZrS 3 by short time reaction at lower temperatures. J. Alloys Compd. 2001, 327, 104-112. [CrossRef]

123. Sarmiento-Pérez, R.; Cerqueira, T.F.T.; Körbel, S.; Botti, S.; Marques, M.A.L. Prediction of stable nitride perovskites. Chem. Mater. 2015, 27, 5957-5963. [CrossRef]

124. Leppert, L.; Reyes-Lillo, S.E.; Neaton, J.B. Electric field- and strain-induced Rashba effect in hybrid halide perovskites. J. Phys. Chem. Lett. 2016, 7, 3683-3689. [CrossRef] [PubMed]

125. Chen, Y.; Lei, Y.; Li, Y.; Yu, Y.; Cai, J.; Chiu, M.-H.; Rao, R.; Gu, Y.; Wang, C.; Choi, W.; et al. Strain engineering and epitaxial stabilization of halide perovskites. Nature 2020, 577, 209-215. [CrossRef] [PubMed]

126. Moloney, E.G.; Yeddu, V.; Saidaminov, M.I. Strain engineering in halide perovskites. ACS Mater. Lett. 2020, 2, 1495-1508. [CrossRef]

127. Kim, H.-S.; Park, N.-G. Importance of tailoring lattice strain in halide perovskite crystals. NPG Asia Mater. 2020, 12, 1-14. [CrossRef]

128. Jones, T.W.; Osherov, A.; Alsari, M.; Sponseller, M.; Duck, B.C.; Jung, Y.-K.; Settens, C.; Niroui, F.; Brenes, R.; Stan, C.V. Lattice strain causes non-radiative losses in halide perovskites. Energy Environ. Sci. 2019, 12, 596-606. [CrossRef]

129. Liu, D.; Luo, D.; Iqbal, A.N.; Orr, K.W.P.; Doherty, T.A.S.; Lu, Z.-H.; Stranks, S.D.; Zhang, W. Strain analysis and engineering in halide perovskite photovoltaics. Nat. Mater. 2021, 20, 1337-1346. [CrossRef] 